\title{
Influence of tribology on global energy consumption, costs and emissions
}

\author{
Kenneth HOLMBERG ${ }^{1, *}$, Ali ERDEMIR ${ }^{2}$ \\ ${ }^{1}$ VTT Technical Research Centre of Finland, VTT FI-02044, Finland \\ ${ }^{2}$ Argonne National Laboratory, Argonne, IL 60439, USA \\ Received: 17 May 2017 / Accepted: 06 July 2017 \\ (C) The author(s) 2017. This article is published with open access at Springerlink.com
}

\begin{abstract}
Calculations of the impact of friction and wear on energy consumption, economic expenditure, and $\mathrm{CO}_{2}$ emissions are presented on a global scale. This impact study covers the four main energy consuming sectors: transportation, manufacturing, power generation, and residential. Previously published four case studies on passenger cars, trucks and buses, paper machines and the mining industry were included in our detailed calculations as reference data in our current analyses. The following can be concluded:

- In total, $23 \%$ (119 EJ) of the world's total energy consumption originates from tribological contacts. Of that $20 \%(103 \mathrm{EJ})$ is used to overcome friction and 3\% (16 EJ) is used to remanufacture worn parts and spare equipment due to wear and wear-related failures.

- By taking advantage of the new surface, materials, and lubrication technologies for friction reduction and wear protection in vehicles, machinery and other equipment worldwide, energy losses due to friction and wear could potentially be reduced by $40 \%$ in the long term (15 years)and by $18 \%$ in the short term (8 years). On global scale, these savings would amount to $1.4 \%$ of the GDP annually and $8.7 \%$ of the total energy consumption in the long term.

- The largest short term energy savings are envisioned in transportation (25\%) and in the power generation (20\%) while the potential savings in the manufacturing and residential sectors are estimated to be $\sim 10 \%$. In the longer terms, the savings would be $55 \%, 40 \%, 25 \%$, and $20 \%$, respectively.

- Implementing advanced tribological technologies can also reduce the $\mathrm{CO}_{2}$ emissions globally by as much as $1,460 \mathrm{MtCO}_{2}$ and result in 450,000 million Euros cost savings in the short term. In the longer term, the reduction can be 3,140 $\mathrm{MtCO}_{2}$ and the cost savings 970,000 million Euros.

Fifty years ago, wear and wear-related failures were a major concern for UK industry and their mitigation was considered to be the major contributor to potential economic savings by as much as $95 \%$ in ten years by the development and deployment of new tribological solutions. The corresponding estimated savings are today still of the same orders but the calculated contribution to cost reduction is about $74 \%$ by friction reduction and to $26 \%$ from better wear protection. Overall, wear appears to be more critical than friction as it may result in catastrophic failures and operational breakdowns that can adversely impact productivity and hence cost.
\end{abstract}

Keywords: friction; wear; energy saving; emission reduction

\section{Introduction}

Transportation, power generation, and manufacturing are vital industrial activities in a highly developed modern society. They involve moving both people and all kinds of materials in many different forms by all types of machines and mechanical systems that have numerous moving parts and hence interacting surfaces.

* Corresponding author: Kenneth HOLMBERG, E-mail: kenneth.holmberg@vtt.fi 
Smooth, reliable, and long-lasting operations of such machines are closely dependent on how well the friction and wear are controlled on their numerous interacting surfaces. The science and technology for understanding and controlling friction, wear, and lubrication of such interacting surfaces in relative motion have been named as tribology since 1966 [1].

The key motivation for establishing the new discipline of tribology was the great economic impact that wear failures had in the British industry and on the British economy in the middle of last century. At the same time, a great number of new technological solutions had been developed that could be used to reduce friction and wear but they had not yet been implemented largely. The Jost report summarised that by large scale implementation of newer and more advanced tribological technologies, 515 million UK pound could be saved annually and this would correspond to $1.36 \%$ of GNP at that time. Most importantly, this report stipulated that such savings could be achieved in a period of ten years. The British government invested 1.25 million UK pound for further development and implementation of tribology in education, research and industry, and ten years later, the savings were estimated to be 200 million UK pound annually [1-4].

The Jost report was followed by other similar studies that reported potential savings of the similar orders of magnitude in Japan (2.6\% of the GNP in 1970), in Germany $(0.5 \%, 1976)$, in the USA $(0.79 \%-0.84 \%, 1977$, $1981)$ and in China $(2 \%-7 \%, 1986)$. The estimated savings show large differences probably due to differences in the level of industrialization and industrial infrastructure of each country, the year when the calculations were carried out and the method of calculations used [4-9].

There has been tremendous progress in understanding of the fundamental mechanisms of tribological phenomena and developing a myriad of new materials, surface technologies, lubricants and other types of technical solutions, such as improved design, for markedly reducing friction and improving wear protection since the time of the Jost report. Furthermore, the greater knowledge gained from worldwide tribological studies mentioned above have been implemented in higher education and industry. However, today we face new challenges in the society due to increased world population, growing demands for energy, and limitation of fossil fuel use due to environmental concerns. In fact, at these days, it has become a great importance for the sustainability of global society to curb the use of fossil fuels and hence reduce the greenhouse gas emissions [10-12].

Figure 1 shows the International Energy Agency (IEA) estimation of key technologies for reduction of $\mathrm{CO}_{2}$ emissions in order to limit the global warming to $2{ }^{\circ} \mathrm{C}$ above pre-industrial levels by 2050 [13]. The largest impact (38\%) is expected to come from end-use energy efficiency and in this area, tribology could contribute considerably with new technical solutions such as new materials and coatings, surface engineering (including surface treatments, modifications, and texturing), new lubricants and additives (including nanomaterials and solid lubricants); new component design with microsensors; new methodologies like biomimetics, nanotechnology and integrated computational material design [12, 14, 15]. These are all related to the concept of "green tribology" which has recently been introduced and defined as the tribological aspects of ecological balance and of environmental and biological impacts [16].

Both the world and the levels of technological achievements have changed much from the years of those earlier tribology impact reports. Still more recent studies on this topic are quite few, so there is a need for an update. Very recently Lee and Carpick [12] prepared a comprehensive report for the Department of Energy in the USA on tribological opportunities for

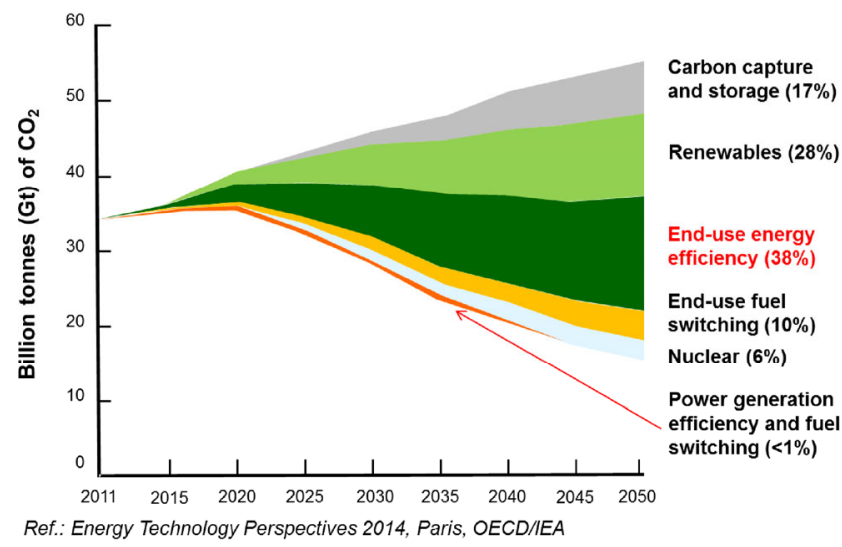

Fig. 1 Key technologies for reduction of $\mathrm{CO}_{2}$ emissions in order to limit global warming to $2{ }^{\circ} \mathrm{C}[13]$. 
enhancing America's energy efficiency. They identified $20 \mathrm{EJ}(2.1 \%$ of the GNP) of energy that could be saved annually through new technologies that can be realized by targeted research initiatives in tribology. However, there is still not to our knowledge any study summarising the impact of tribology on a global level.

We have earlier calculated the impact of friction on global energy consumption in passenger cars, trucks and buses, and paper machines, and the impact of both friction and wear in the mining industry [15, 17-19]. Our intention with this work is to assess the influence of friction and wear in energy consumption, economic losses, and $\mathrm{CO}_{2}$ emissions worldwide in the four main energy consuming sectors: transportation, industry, energy industry, and residential, and then to estimate potential savings that can be gained by putting into use of new tribological solutions that came about during the last decade or so. This is done based on the data from the four previous case studies and from other publications that we could find in the open literature.

\section{Methodology}

The global calculations used in this paper were carried out according to a methodology that was developed by Holmberg et al. [17] for the calculation of the impact of friction on passenger cars and in an industrial case study, i.e., paper machines mentioned earlier. The same methodology was later extended also to include the impact of friction and wear in mining [15]. The methodology is based on the combination of the analyses of several physical phenomena resulting in the consumption of energy in mechanical equipment. It includes the following analyses and calculations:

1. An estimation of the global energy consumption in targeted economic sectors.

2. Calculation of friction, wear, and energy losses in components and machinery used in such sectors.

3. Estimation of their operational effects.

4. Estimation of tribocontact-related friction and wear losses today and in the future.

5. Calculation of the global energy consumption today due to friction and wear and potential savings in the short and long runs.

Figure 2 shows the calculation methodology as used for passenger cars. First step is the estimation of annual fuel consumption found in reliable statistics divided by the number of cars worldwide which gives the energy used in one global average car. Based on statistics, a technical specification for a global average passenger car as well as global average operational conditions are defined. The components of this global average passenger car are then considered and the friction part is estimated and further broken down into microscale lubrication and contact mechanisms. The level of typical coefficients of friction in the global average car components is defined based on data from published literature. Similar levels of coefficients of friction for new cars, the lowest levels measured in laboratories so far, and estimated levels in future 2025 are estimated. This data is upscaled to global level and the global energy consumption due to friction as well as potential fuel, cost and $\mathrm{CO}_{2}$ savings are then calculated as illustrated in Fig. 2.

The calculations were carried out on the basis of

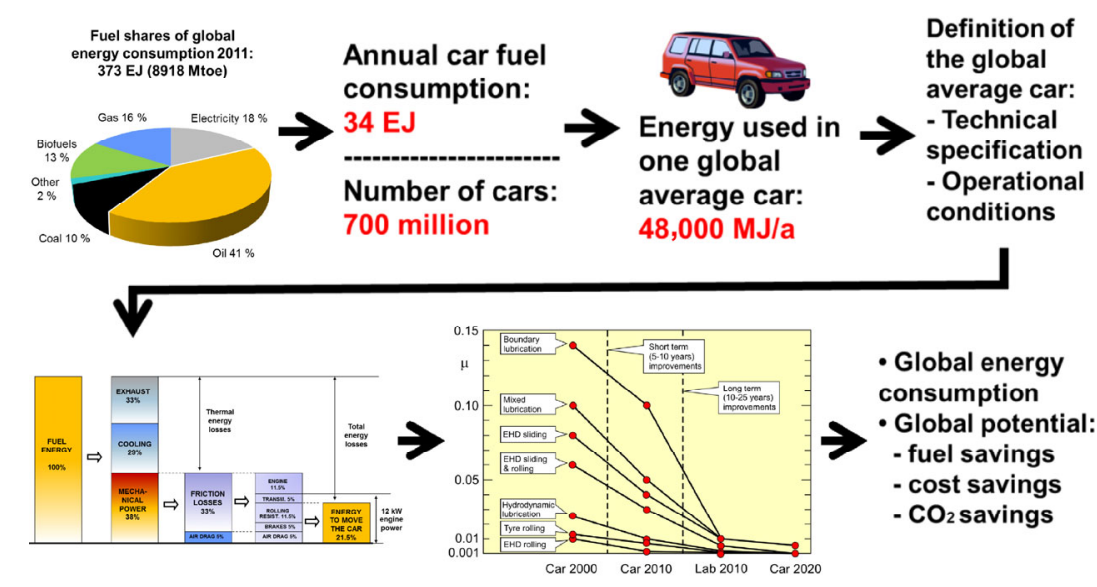

Fig. 2 Methodology for calculating global impact of friction on fuel consumption in passenger cars and potential savings [17]. 
scientific publications and reports, publically available statistical data, unpublished data received directly from some operators and the authors' own experience.

\section{Energy consumption worldwide}

The total amount of energy generated from various energy sources like coal, oil, gas, nuclear, wind, etc., is called the total primary energy supply (TPES). The TPES for a region is the energy generated in that region + imports - exports. The global TPES was 575 EJ (13,700 Mtoe) in year 2014 and of that 167 EJ was used by the energy or power generation industry to produce electricity and heath, 12 EJ was the amount of energy lost during transfer and other losses, and the rest forms the total energy consumption, called total final consumption (TFC), as shown in Fig. 3 [20, 21].

The total consumption of energy worldwide was 396 EJ (9,425 Mtoe) in the year 2014 and it was distributed as follows [20]:

$-29 \%$ for industrial activity;

$-28 \%$ for transportation;

$-34 \%$ for domestic, including residential, services, agriculture, forestry, etc.;

$-9 \%$ for non-energy use, typically as raw materials.

\section{Impact of friction and wear on energy consumption, economic losses, and emissions}

From our previous case studies, we have as reference data in our calculations providing detailed information on the impact of friction from road vehicles, which account for $75 \%$ of the energy consumption in transportation sector. In the industrial sector, we have as reference data from one study focusing on how friction impacts a very advanced automated high-tech manufacturing industry, i.e., the paper production; and in another study focusing on how friction and wear impact a well-established heavy-duty but lowtech industry; the mining sector, see Fig. 3.

With regard to wear, there is detailed data only from one of the sectors we examined in the past; the mining industry, in which wear is very significant and far more important compared to other industrial sectors which do not suffer the same levels of wear. The mining study showed that of the total maintenance costs in mining, about half is due to the manufacturing of wear replacement parts and the other half originates from maintenance, down time, and labour costs [15].

In our calculations, we assume that the maintenance costs are in direct relation to the costs of wear parts and we use the data on maintenance costs in different sectors, see Fig. 4, for estimating the costs due to wear in these economic sectors [22].

In the following sections, we will estimate the energy losses due to friction and wear in the four large energy consuming sectors: namely, transportation, industry, energy industry, and residential. The industry sector represents the production and manufacturing industry while the energy industry represents the power plants for power generation and for thermal heating.

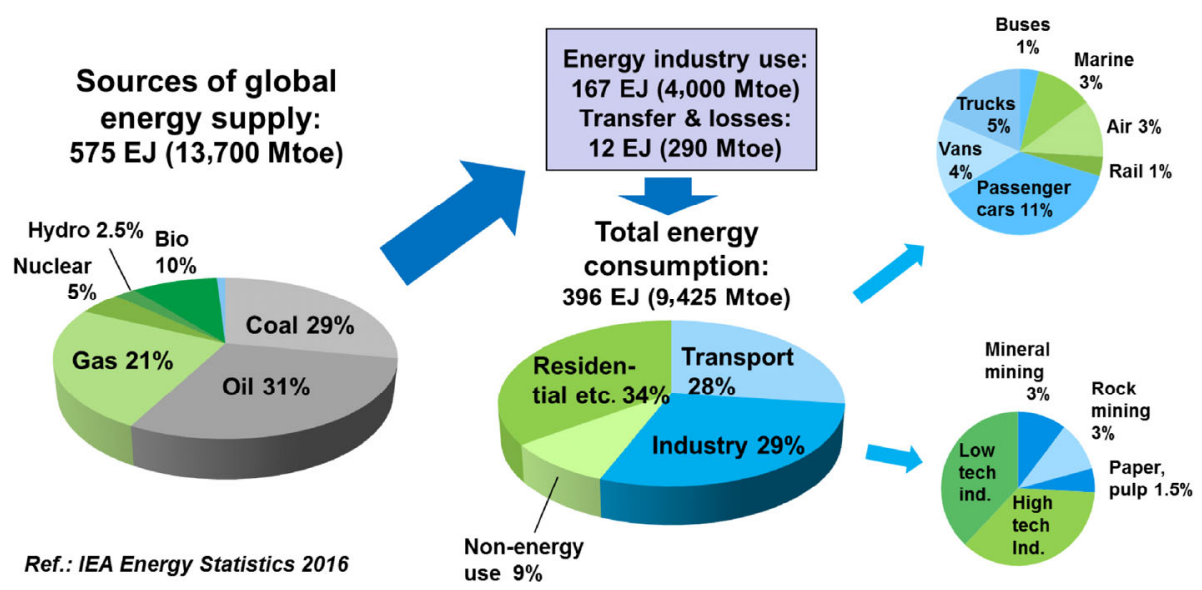

Fig. 3 Global energy supply and consumption in main economic sectors 2014. Mtoe = million tonnes of oil equivalent. 


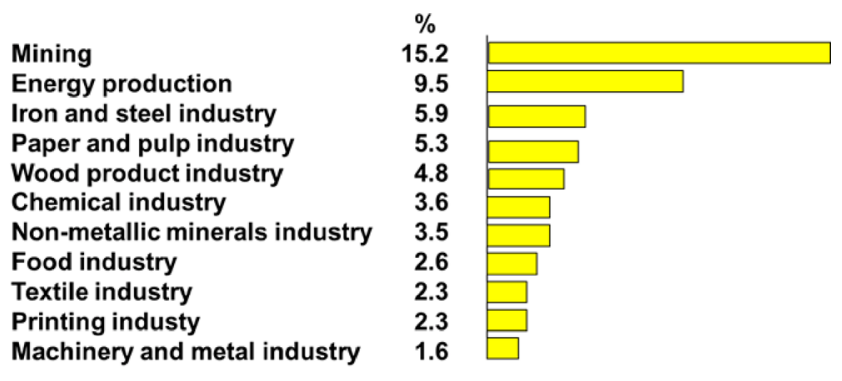

Fig. 4 Maintenance costs in industrial sectors in Finland in 1997.

\subsection{Industry}

The biggest industrial energy users are the chemical and petrochemical industry (30\%) and the iron and steel industry (19\%) that together consume half of the total energy used by all industrial sectors. Other large industrial energy users are the non-metallic minerals industry (9\%, mainly cement), paper and pulp industry $(6 \%)$, food and tobacco industry $(5 \%)$, machinery industry $(4 \%)$, and non-ferrous metals industry $(4 \%$, mainly aluminium), see Fig. 5 [13, 23].

Our previous study on paper machines showed that $32 \%$ of the electrical power used goes to overcome friction. However, the electricity used for mechanical energy is only $30 \%$ of the total energy use as $70 \%$ of the energy consumption is due to thermal energy for process heating. The energy consumed in a paper mill to overcome friction is in the range of $15 \%-25 \%$ [18]. In mining, on the other hand, where heavy rock materials are extracted, crashed, and transported, $40 \%$ of the energy consumption goes to overcome friction [15]. Based on this, we estimate that in industry in average, about $20 \%$ of the energy goes to overcome friction in total.

The share of energy losses due to wear in industry is calculated based on the data from mining industry [15]. In mining, the energy losses due to wear is $43 \%$ of that of friction. The wear-related energy losses include energy used for producing new parts for wear part replacement and downtime spare equipment. The cost for wear parts in mining is about the same order as the maintenance costs. We assume that also in other sectors, the cost for wear parts is proportional to the maintenance costs and we use proportion of maintenance costs of total costs for each sector presented in Fig. 4 [22]. This indicates that the cost of wear parts in industry in general is about one third of that in mining. In the case of machinery and metal industry, it is one tenth of that in mining. Thus we use for industry in total that the energy used for wear losses is $14 \%$ of that used to overcome friction.

The costs related to wear include not only the costs for wear part replacement and downtime, spare equipment, but also the costs for maintenance work which is not energy related. The costs due to wear in mining industry are $106 \%$ of the costs due to friction. We estimate the same relation between costs in the four sectors as it was for the energy losses. Thus the cost for wear in industry is $35 \%$ of the cost for friction, see Table 1.
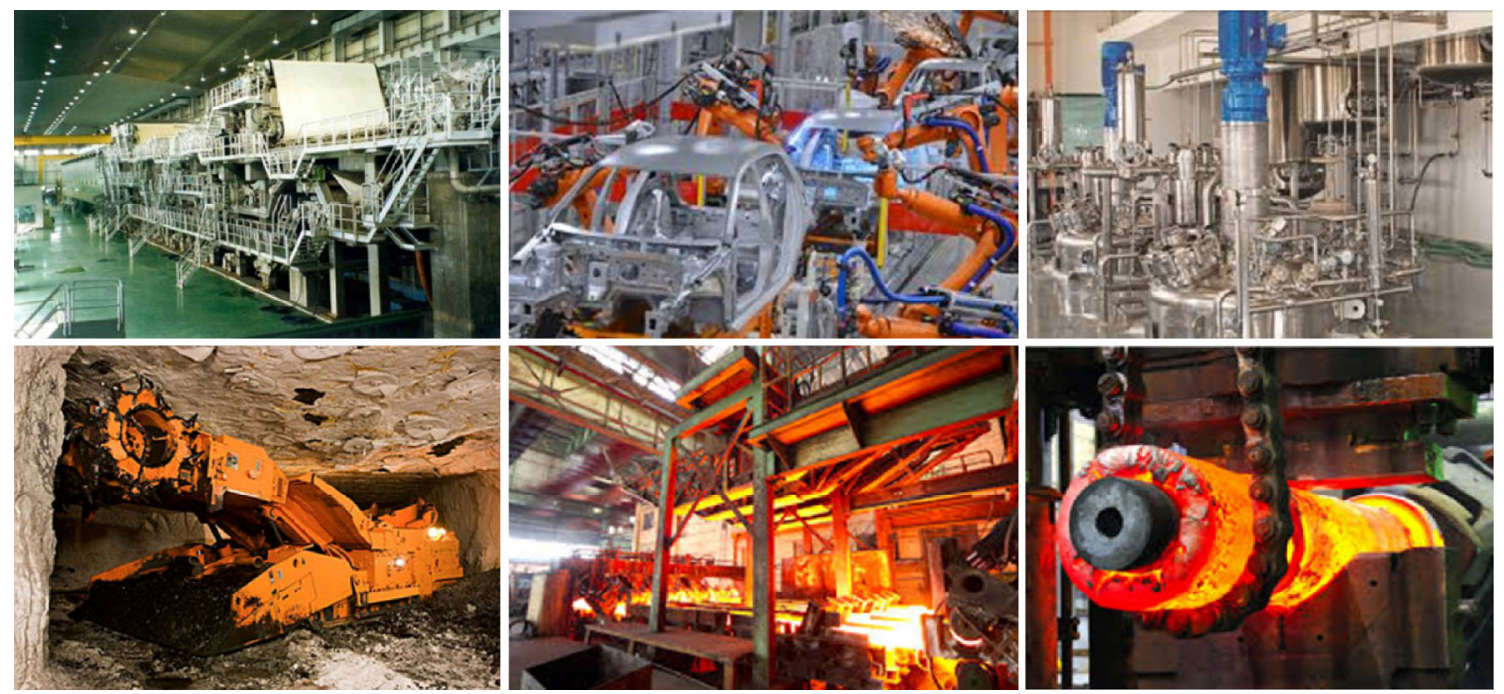

Fig. 5 Production machines in paper, car, food, mining and steel industry. 
Table 1 Comparison of energy and costs due to friction and wear for the four economic sectors.

\begin{tabular}{cccc}
\hline & $\begin{array}{c}\text { Energy to overcome friction as part } \\
\text { of total energy use }\end{array}$ & $\begin{array}{c}\text { Energy due to wear compared to } \\
\text { energy loss due to friction }\end{array}$ & $\begin{array}{c}\text { Costs due to wear compared to } \\
\text { costs due to friction }\end{array}$ \\
\hline Unit & $\%$ & $\%$ & $\%$ \\
Transportation & 30 & 10 & 22 \\
Industry & 20 & 14 & 35 \\
Energy industry & 20 & 22 & 53 \\
Residential & 10 & 14 & 35 \\
Total & 20 & 15 & 37 \\
\hline
\end{tabular}

\subsection{Transportation}

At present, the transportation sector includes about 1,600 million vehicles [24] used for transportation of people and freight in sea, land, and air (see Fig. 6). Road vehicles use 83EJ energy annually, which is $75 \%$ of the total energy use in transportation. The ships are the biggest energy users as calculated by the total energy use per vehicle. The average annual energy use per ship is 120,000 GJ. A road vehicle uses in average 80 GJ annually, a train 33,000 GJ, and an air plane 33,000 GJ. However, ships are the largest carriers of

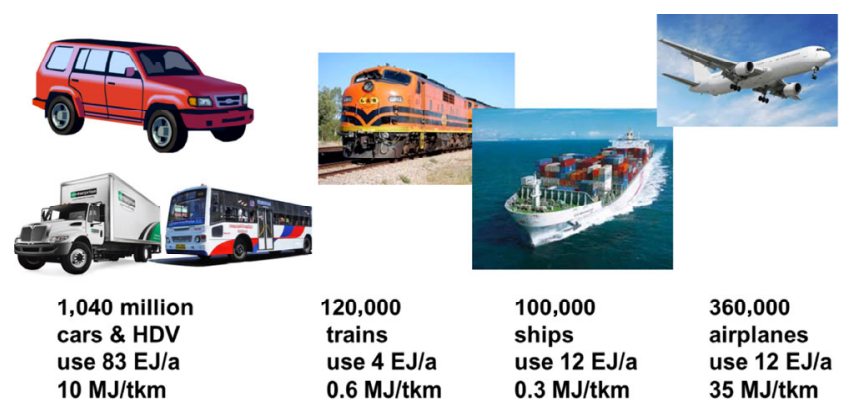

Fig. 6 Number of transportation vehicles worldwide and their global annual energy consumption and energy intensity (energy consumption per tonne weight transported and kilometre). world freight and people by weight $(73 \%)$ followed by road vehicles (15\%), train (12\%) and aviation $(0.6 \%)$ $[25,26]$. The energy intensity, defined here as the energy used to transport one tonne freight or people one kilometre, is for ships $0.3 \mathrm{MJ} / \mathrm{tkm}$, for railway $0.6 \mathrm{MJ} / \mathrm{tkm}$, for road vehicles $10 \mathrm{MJ} / \mathrm{tkm}$ and in aviation $35 \mathrm{MJ} / \mathrm{tkm}$, see Table 2 [13, 25-31].

Road vehicles use 83 EJ annually and of that is $32 \%$ used to overcome friction [24]. There are no previous calculations available on the share of frictional energy consumption in rail, marine, and aviation. However, the share of friction in aviation is estimated to be about $10 \%$ while it is $20 \%$ in both marine and rail by considering the mechanical structures of those vehicles. Based on this, we can conclude that in transportation, with all sectors included, $30 \%$ of the energy use goes to overcome friction, see Table 1.

For the estimation of wear, data from the industrial sector is used as reference data, see section 4.1 above. The share of energy losses due to wear in transportation is estimated to be smaller than that in the industrial sector and about one fifth of that is in mining. It means that the energy loss due to wear is only $10 \%$ of the energy used to overcome friction and the cost due to wear is $22 \%$ of that due to friction. The low level of

Table 2 Key energy and energy efficiency figures in transportation.

\begin{tabular}{|c|c|c|c|c|c|c|}
\hline & $\begin{array}{c}\text { Number of } \\
\text { vehicles worldwide }\end{array}$ & $\begin{array}{c}\text { Global } \\
\text { energy use }\end{array}$ & $\begin{array}{c}\text { Energy use / } \\
\text { vehicle }\end{array}$ & $\begin{array}{c}\text { Part of global } \\
\text { transport } \\
\text { energy use }\end{array}$ & $\begin{array}{l}\text { Part of global } \\
\text { transport by weight } \\
\text { and distance }\end{array}$ & $\begin{array}{l}\text { Energy } \\
\text { intensity }\end{array}$ \\
\hline Unit & & $\mathrm{EJ} / \mathrm{a}$ & $\mathrm{GJ} / \mathrm{a}$ & $\%$ & $\%$ & $\mathrm{MJ} / \mathrm{tkm}$ \\
\hline Road vehicles & $1,040 \times 10^{6}$ & 83 & 80 & 75 & 15 & 10 \\
\hline Trains & 120,000 & 4 & 33,000 & 4 & 12 & 0.6 \\
\hline Ships & 100,000 & 12 & 120,000 & 11 & 73 & 0.3 \\
\hline Airplanes & 360,000 & 12 & 33,000 & 11 & 0.6 & 35 \\
\hline Total & $1,620 \times 10^{6}$ & 110 & & 100 & 100 & 2 \\
\hline
\end{tabular}


wear loss in transportation is explained by the very advanced materials and highly optimised lubrication technologies implemented in vehicles where part replacement or remanufacture is a much smaller issue than in many other sectors like mining.

\subsection{Energy industry}

The energy industry includes a large range of electricity power plants, combined heat and power plants, heat/ steam plants, blast furnaces, gas works, coke ovens, oil refineries, liquefaction plants, etc. Like in the industrial sector, a great part of the energy use is thermal energy for heating. A lot of moving tribological contacts is found in power generation, such as in steam and gas turbines, hydro turbines, generators, pumps, conveyors, coal mining machines, drilling and production equipment, see Fig. 7(a) [12, 13, 20, 32].

Again detailed data on the energy consumption in mechanical equipment in the energy industry and the role of friction are hard to find in open literature. We estimate that the energy industry has a similar structure as the industrial sector where a considerable amount of the energy used is thermal energy for process heating. Based on this, we estimate that in total about $20 \%$ of the energy is used to overcome friction.

The share of energy losses and costs due to wear in energy industry is estimated to be half of that in mining. Thus the energy loss due to wear is estimated to be $22 \%$ of that due to friction and the costs due to wear are $53 \%$ of that due to friction.

\subsection{Residential and services}

Residential, service sector, and public buildings use a large range of energy conversion and utilization technologies. They are used in space heating and cooling/ventilation systems, in steam generation, water and heating systems, in lightning, in house-hold appliances, consumer products and in business equipment, see Fig. 7(b) [13]. The buildings have a very long life span, 40-120 years, and so has also a major part of the energy-consuming equipment, 5-20 years. A major part of the energy consumption is for space heating and cooling, and for water heating. The mechanical systems that need energy are ventilation systems, fans, pumps, etc. We estimate that $10 \%$ of the total energy use is for overcoming friction in these systems [13].

The share of energy losses due to wear in residential and services equipment is estimated to be one third of that in mining industry, being thus $14 \%$ of the energy used to overcome friction. The cost due to wear is $\sim 35 \%$ of that due to friction.

\subsection{Costs and emissions}

The economic impact of friction and wear is calculated based on the costs for energy consumption to overcome friction, the costs of energy needed to manufacture wear related replacement parts and spare equipment, and cost for wear related maintenance work. A global average price of $18 €$ for $1 \mathrm{GJ}$ energy or $1 \mathrm{TJ}=18 \mathrm{k} €$ is used [15]. (a)

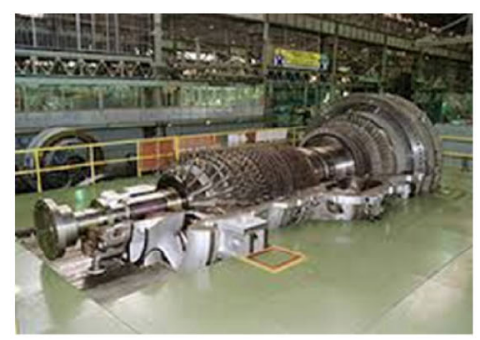

(b)
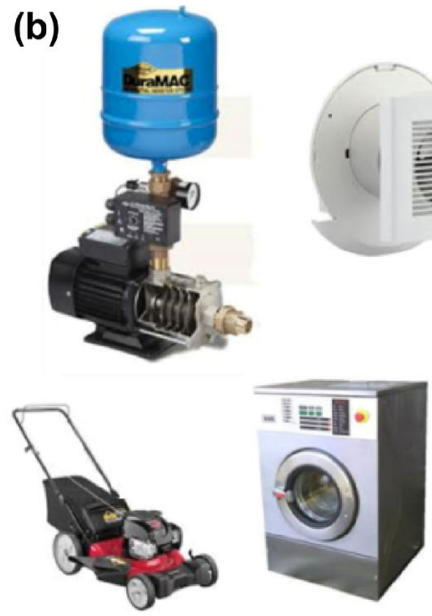
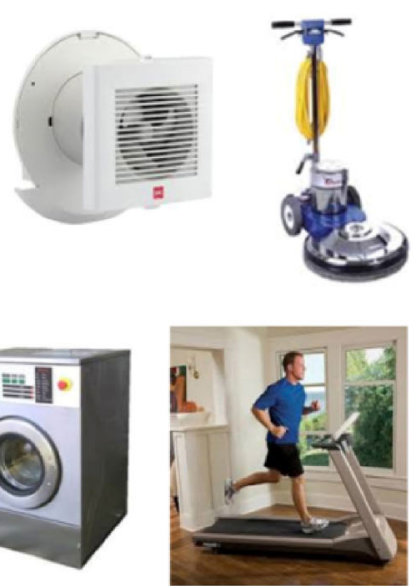

Fig. 7 Power plant gas turbine (a) and typical residential machines (b). 
The energy production and consumption is the dominating component in global greenhouse gas emissions and it forms $76 \%$ of the total emissions while agriculture, forestry and other land use form $24 \%$, see Fig. 8.

The friction and wear related $\mathrm{CO}_{2}$ emissions are calculated assuming that they are proportional to the energy consumption. This is a fair approximation on global scale even if there are differences in the level of emissions in the various economic sectors. The energy consumption of $1 \mathrm{PJ}$ results in $0.0683 \mathrm{MtCO}_{2}$ $\left(=36,000 \mathrm{MtCO}_{2} / 527 \mathrm{EJ}\right)$ carbon dioxide emissions on average global level.

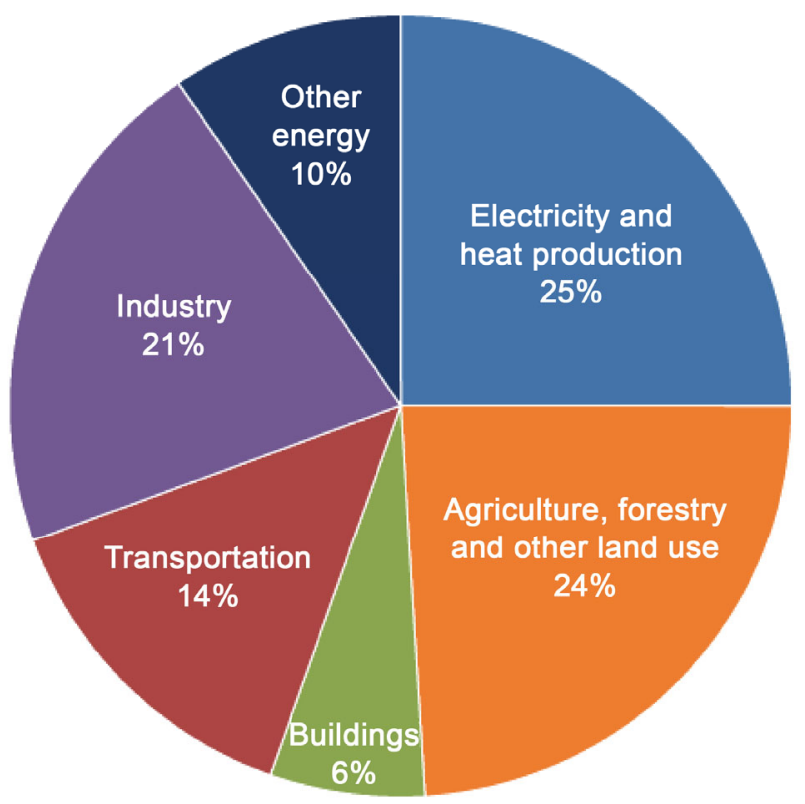

Fig. 8 Global greenhouse gas emissions by economic sector [10].

\section{Impact of tribology and friction and wear reduction}

\subsection{Potential reduction in friction and wear}

There has been a huge development in finding new tribological solutions to reduce friction and wear over the last decades [15, 17-19]. This development is illustrated in Fig. 9 where the typical friction coefficients in tribological contacts in trucks and buses in average today, in today's new commercial vehicles, lowest values measured in research laboratories today, and values predicted for future vehicles in year 2025 are shown according to contact and lubrication mechanisms.

The mechanical devices used in the four economic sectors, the level of new technological solutions implemented and operational conditions are considered. Based on that, the average friction and wear levels of today's devices are calculated and compared to the relative friction and wear reduction in today's new commercial devices, lowest levels measured in research laboratories today and levels estimated to be possible to achieve in future up to year 2030, see Table 3. These levels are named in the following as "Average 2017", “New 2017", "Laboratory 2017" and "Future 2030". The new technological solutions to achieve these reductions are presented in Section 7.

\subsection{Tribological impact today and in the future}

The global friction and wear losses, the economic expenditure and $\mathrm{CO}_{2}$ emissions for each sector and in total were calculated using the data, criteria and

Table 3 Estimated relative friction and wear rate reduction trends based on data presented in Section 7 and literature [15, 17-19].

\begin{tabular}{|c|c|c|c|}
\hline & \multicolumn{3}{|c|}{ Relative friction and wear reduction } \\
\hline & $\begin{array}{c}\text { From Average } 2017 \text { to } \\
\text { New } 2017\end{array}$ & $\begin{array}{c}\text { From Average } 2017 \text { to } \\
\text { Lab } 2017\end{array}$ & $\begin{array}{c}\text { From Average } 2017 \text { to } \\
\text { Future } 2030\end{array}$ \\
\hline & $\%$ & $\%$ & $\%$ \\
\hline \multicolumn{4}{|l|}{ Friction reduction } \\
\hline - Transport and energy industry & 40 & 70 & 80 \\
\hline - Industry and residential & 40 & 80 & 90 \\
\hline \multicolumn{4}{|l|}{ Wear reduction } \\
\hline - Transport and energy industry & 30 & 40 & 50 \\
\hline - Industry and residential & 40 & 60 & 70 \\
\hline
\end{tabular}




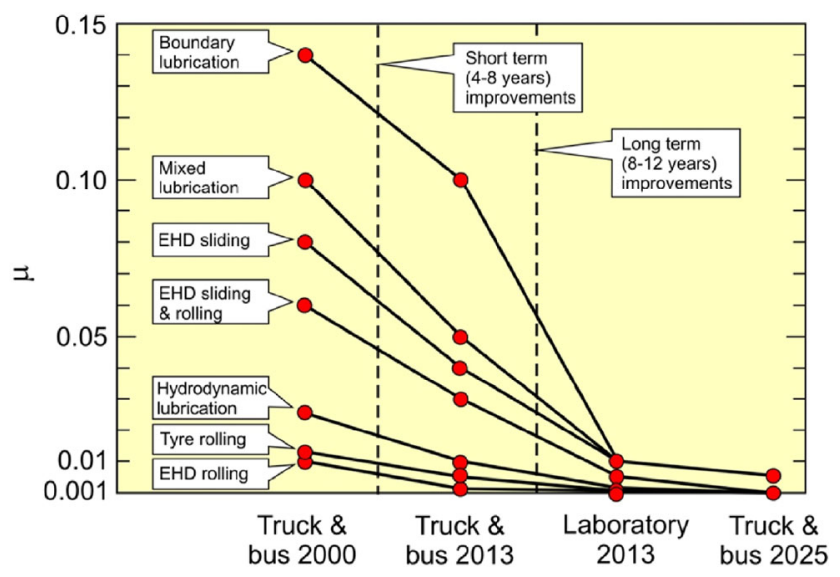

Fig. 9 Trends in the reduction of the coefficient of friction in trucks and buses for different lubrication mechanisms and for rolling friction [19].

assumptions presented above in Sections 3 and 4, and are shown in Appendix 1. The calculations show that today $103 \mathrm{EJ}$ of energy is used to overcome friction worldwide and in addition, wear causes 16 EJ energy loss. The total costs of friction and wear globally are 250,000 million Euro and the total $\mathrm{CO}_{2}$ emissions due to friction and wear are $8,120 \mathrm{MtCO}_{2}$. Corresponding cost estimates for friction and wear losses according to New 2017, Laboratory 2017 and Future 2017 are given in Appendix 1.

This is the first time to our knowledge that impact of both friction and wear has been estimated in detail on this level. Figure 10 shows a comparison of the impact of friction and wear on global level. Both with regard to energy losses and $\mathrm{CO}_{2}$ emissions is the impact of friction six times higher than that of wear while with regard to economic impact, the friction impact is three times that of wear impact.

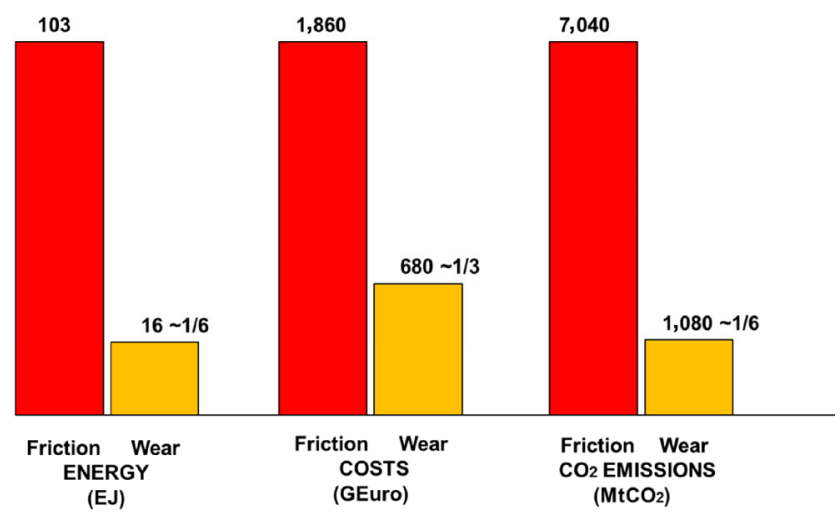

Fig. 10 Energy consumption, costs and $\mathrm{CO}_{2}$ emissions due to friction and wear globally.

\section{Potential savings by tribological advances}

In the four case studies, the potential savings by implementing new tribological solutions were calculated both on the short term and on long term, as shown in Figs. 9 and 11, see also Appendix 3. The manufacturers of trucks and buses are more advanced and very quick in implementing new technologies in their products and there are big fleets with a limited number of owners so the implementation time is considered quite short. This is not the case in the mining industry with many owners with scepticisms or negative attitudes toward the deployment of new technologies. Paper machines are somewhat more advanced but due to the long lifetime of the machines, the implementation of new technologies does take time due to return on existing investment policies.

The average implementation time in all sectors was in this study estimated to be 8 years representing short term and 15 years representing long term based on considerations of the structure of the four sectors, average product lifetime and typical willingness to implement new technology in products. The savings by implementing new friction and wear solutions was calculated both on short term and on long term, see Appendix 2.

The implementation of new technology largely worldwide would save in the short term $21.5 \mathrm{EJ}$ energy, 455,000 million Euro and 1,460 $\mathrm{MtCO}_{2}$ emissions. In the long run, the savingscould easily amount to 46 EJ energy, 973,000 million Euro and 3,140 $\mathrm{MtCO}_{2}$ emissions. The savings would be $1.39 \%$ of the GNP and $8.7 \%$ of the total global energy consumption for the time scale of 15 years.

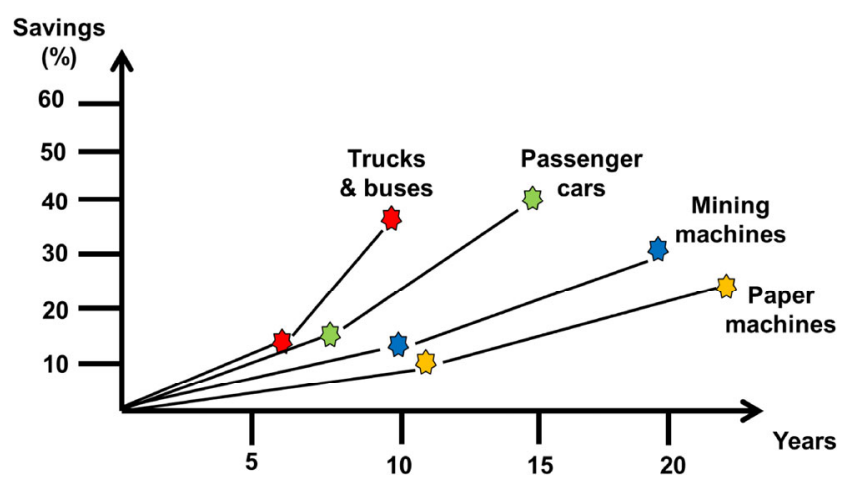

Fig. 11 Calculated potential savings over current state of the art by the introduction of advanced tribology solutions in four case studies and their time scale of implementation. 
The biggest potential savings that can be achieved in the timescale of 8 years are in the transportation and energy industry sector, as shown in Fig. 12. The implementation takes longer time in the industry and residential sectors so the short term savings are not that high. The potential savings in some geographic regions are also shown in Table 4.

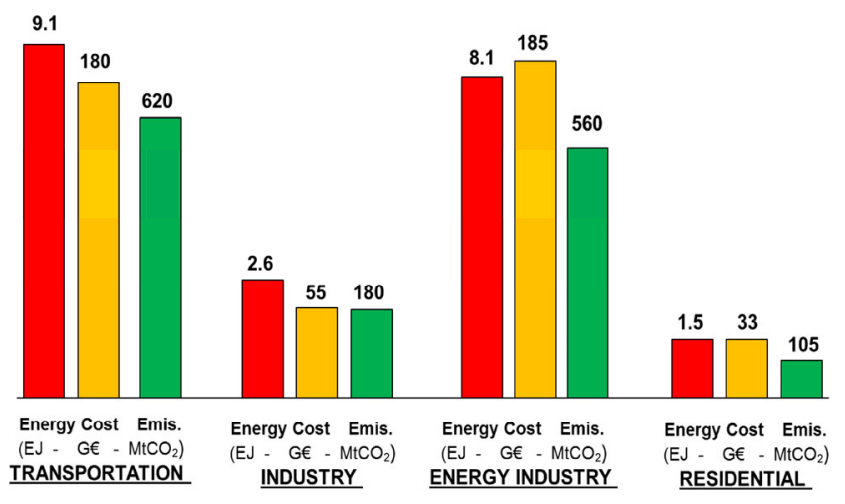

Fig. 12 Potential annual energy, cost and $\mathrm{CO}_{2}$ emission savings globally after 8 years of intensive advanced tribology implementation.

\section{Means and technologies to reduce friction and wear}

In this section, we present some of the latest technological advances that can be implemented to achieve the levels of friction and wear reductions mentioned in charts and tables above. These examples mainly describe what we have named "today's best solution on the laboratory level" (Lab 2017). Some of the newest solutions for friction and wear reduction can be directly implemented or retrofitted by the users to existing machines but others may only be viable in newer or more advanced machines. Such are the changes to new type of engine lubricant, lubricant additives and tires with new materials and new design, as well as frequently replaced wear parts in other sectors. On the other hand, many of the new friction and wear reducing solutions need re-design or replacement of existing components, like the introduction of new materials, surface treatments, coatings

Table 4 Estimated potential energy and cost savings, and $\mathrm{CO}_{2}$ emission reduction on long term (15 years) by region calculated as related to the total primary energy supply (TPES) of each region.

\begin{tabular}{|c|c|c|c|c|c|}
\hline & TPES & $\begin{array}{c}\text { Share of global } \\
\text { TPES }\end{array}$ & Energy savings & Cost savings & $\begin{array}{l}\mathrm{CO}_{2} \text { emission } \\
\text { reduction }\end{array}$ \\
\hline Unit & Mtoe & $\%$ & $\mathrm{PJ} / \mathrm{a}$ & Million Euro/a & Million tonnes/a \\
\hline World & 13,700 & 100 & 46,000 & 973,000 & 3,140 \\
\hline $\begin{array}{l}\text { Industrialized } \\
\text { countries }\end{array}$ & 8,220 & 60 & 27,600 & 583,800 & 1,884 \\
\hline $\begin{array}{c}\text { Industrially } \\
\text { developing countries }\end{array}$ & 4,800 & 35 & 16,100 & 340,550 & 1,099 \\
\hline $\begin{array}{l}\text { Agricultural } \\
\text { countries }\end{array}$ & 685 & 5 & 2,300 & 48,650 & 157 \\
\hline China & 3,066 & 22.4 & 10,304 & 217,952 & 703 \\
\hline USA & 2,216 & 16.2 & 7,452 & 157,626 & 509 \\
\hline EU-28 & 1,606 & 11.7 & 5,382 & 113,841 & 367 \\
\hline India & 825 & 6.0 & 2,760 & 58,380 & 188 \\
\hline Russia & 710 & 5.2 & 2,392 & 50,596 & 163 \\
\hline Japan & 442 & 3.2 & 1,472 & 31,136 & 100 \\
\hline Brazil & 303 & 2.2 & 1,012 & 21,406 & 69 \\
\hline Canada & 280 & 2.0 & 920 & 19,460 & 63 \\
\hline UK & 180 & 1.3 & 598 & 12,649 & 41 \\
\hline Finland & 34 & 0.25 & 115 & 2,433 & 8 \\
\hline
\end{tabular}


and textured components or new design solutions. This kind of improvements need to be introduced by the machine producers and will come out on the market, when the new products are launched.

New technologies for friction and wear reduction are summarised below based on more detailed descriptions in six previously published reports $[12,15,17-$ $19,24]$ and some additional recent publications.

\subsection{Lubricants}

Mineral-based oil is the traditional way of lubricating sliding components and still constitutes the largest consumption by volume in the world. Syntheticbased oils are in the rise and increased in usage over the years due to their much attractive thermal and oxidative stability and longer life. Both oils provide good tribological properties as they wet and attach effectively to a steel surface, provide low shear between the sliding surfaces, and have a good load carrying capacity even under highly loaded line or point contacts. By and large, these oils still represent the largest volumes used in transportation and other industrial sectors. The load carrying property has been improved over the years by advances in viscosity index improvers, anti-wear, and anti-friction additives. Tribological research has shown that there are several ways to further improve the performance of traditional mineral oil lubrication such as:

1. Nanotechnology based anti-friction and antiwear additives. The structure, property, and performance characteristics of the lubricant film are especially important in the very thin, elasto-hydrodynamic (EHD), and boundary lubricated (BL) contacts. The protecting fluid and boundary film thickness may be only a few micrometres and in many cases even much below one micrometre. Such contacts may be heavily loaded in certain applications by a nominal contact pressure of up to 3-4 GPa and these oils are still expected to provide low shear and good protection against wear and scuffing. As a result of concerted efforts, very low friction, even as low as a coefficient of friction of 0.005 , has been measured in the presence of friction modifier additives like glycerol mono-oleate (GMO) or pure glycerol when lubricating tetragonal amorphous carbon coatings [33-35]. Nanomaterials with very promising tribological properties under investigation are carbon-based additives including nano-diamonds, onion-like carbons, carbon nanotubes, graphene, graphite as well as some inorganic fullerenes of transition metal dichalcogenides, like $\mathrm{MoS}_{2}$ and $\mathrm{WS}_{2}$, and copper, polymeric and boron-based nanoparticles [36-43].

2. Low viscosity oils. Our analysis has shown that viscous losses and shear in hydrodynamic contacts (HD) result in significant energy losses. If the lubricant viscosity can be further reduced while the low-friction and anti-wear functions are maintained, a very large energy saving in engines could be achieved [44, 45]. One alternative to mineral and synthetic-based hydrocarbon oils is the polyalkylene glycol (PAG)based lubricants with lower viscosity and better environmental compatibility [46]. The use of organic friction modifiers [47], liquid crystal mesogenic fluids [48] and ionic liquids [49-52] have also provided low friction when used as additives in lubricating oils. Coefficients of friction even below 0.001 has been reported when using in a series of novel additives in such fluids [53]. Under conditions involving the uses of a mild acidic liquid and a metallic and/or ceramic material, friction coefficients of less than 0.01 have been achieved by triggering repulsive double-layer forces through the generation and adsorption of hydrogen, hydroxyl and hydronium ions on the opposing surfaces [54]. It has been suggested that by introducing artificial boundary slippage in HD journal bearings, the load carrying capacity can be considerably increased while the friction is reduced by $60 \%$ [55].

3. Vapour phase lubrication. In many lubricated tribological contacts, for example in roller bearings, the volume of the lubricant that is effective and needed for the tribological action in the contact is only a small fraction of the lubricant volume that is provided to the system. The non-active volume of the lubricant causes viscous losses. Such losses are very much reduced in vapour phase lubrication where a stream of gas transports the vaporised lubricant to the mechanical system. Vapour phase lubrication is especially beneficial in high temperature environments where liquid oil lubrication cannot operate and in microelectromechanical systems (MEMS) where the capillary effect of liquid lubrication is a problem $[12,56-60]$. 


\subsection{Materials}

The materials used in tribological components have a big influence on both wear and friction. Search for new and more effective material solutions has intensified in recent decades for increased toughness, strength, hardness, all of which impact durability, and light-weightiness which also improves efficiency in vehicles. At the same time, a myriad of novel solid lubricants and their coatings has been developed to reduce wear and friction in both dry and lubricated contacts by even orders of magnitude. In particular, low-dimensional materials (such as Bucky-balls, nanotubes, nanosheets, and nano-onions of carbonand boron-based solids as well as various transition metal dichalcogenides) have been proven to be very effective in reducing friction and wear of sliding surfaces under dry and lubricated contacts. Besides these, there have been significant strides in surface treatment and engineering fields providing very thick, hard, and slick surfaces for severe tribological applications involving abrasive, erosive, or adhesive wear. All and all, nowadays, there exist several innovative materials technologies that can improve the friction and wear properties of tribological components. Some of these advances are summarized below:

1. New materials. The erosive wear can be reduced by changing traditional cast iron to rubber coated surfaces in, e.g., pumps and pipe lines. Change from metallic component to polymers will normally reduce friction while ceramics are tribologically beneficial to use both in oil and water lubricated contacts [61]. Recently, research efforts in high-entropy alloys intensified and mainly because of their very distinct structures and compositions, they were shown to exhibit unusual physical and mechanical properties [62] as well as impressive resistance to wear and corrosion $[63,64]$. Further, a new breed of non-ferrous materials (such as aluminium) named covetics consisting as much as $6 \mathrm{wt}$.\% carbon has recently been developed and promises to offer much enhanced mechanical and hence tribological properties in lightweight $\mathrm{Al}$ alloys potentially making them suitable for sliding powertrain applications [65]. Although not new, a class of new nickel-titanium alloys, e.g., Nitinol 60 were shown to combine high hardness with superelasticity enabling unusual load-bearing capacity and other desirable tribological attributes [66]. Under boundary lubricated conditions with castor oil, such alloys were shown to exhibit friction coefficients below 0.01 [67].

2. Material treatment and surface modification. The increase of surface hardness, toughness and wearresistance can be achieved by a variety of methods. Case carburizing, nitriding, or boronizing are classical examples that have been in use for many decades to combat friction and wear under abrasive, adhesive, and erosive conditions. More exotic methods such as shot-peening $[68,69]$ and friction-stir processing [70] were shown to structurally modify top surfaces at micro/nano-scales which in turn provide much improved friction and wear properties under both dry and lubricated conditions [71]. During the past decade, interest in additive manufacturing has grown exponentially for making three dimensional objects initially from polymers, but lately from metal or ceramic powders for all kinds of applications [72-74]. Tools used in additive manufacturing have become very versatile to manufacture $3 \mathrm{D}$ objects that can also incorporate super-hard and/or self-lubricating solids for improved friction and wear properties in numerous applications $[75,76]$. The incorporation of hard and low-friction materials onto the top surfaces by various techniques including laser surfacing, particle plasma ablation, etc., can substantially increase hardness, stiffness and wear performance of the surfaces [77, 78]. The interest in cold-spray processes for friction and wear control has also intensified in recent years. They have the potential of alleviating thermal distortions and residual stress build-up which are very common with laser cladding and other similar techniques which are also used for enhanced wear resistance. They are particularly attractive for low-melting point $\mathrm{Al}$ and Mg alloys [79].

Traditional thermal diffusion processes, such as nitriding, carburizing, vanadizing, and boriding or boronizing are still used extensively to improve corrosion, mechanical and tribological properties of ferrous alloys. In these processes, nitrogen, carbon, or boron diffuse into the near surface regions of the workpieces and react with the metallic constituents, like $\mathrm{Fe}$, and thus form thick and hard reaction layers. 
Compared to quenching, such thermal diffusion processes can provide much higher resistance to corrosive, adhesive, abrasive, and erosive wear. All the thermal diffusion processes mentioned are unfortunately very slow. It may take several hours to whole day to achieve desired thicknesses or case depths. They are also energy intensive and environmentally unfriendly as they produce large volumes of $\mathrm{CO}_{2}$ and hence expensive. Recently, an ultra-fast boriding process was developed which reduced the processing time to minutes, i.e., achieving $50 \mu \mathrm{m}$ thick boride layer in $15 \mathrm{~min}$ instead of 6-8 hours with conventional pack-boriding method. It was demonstrated that such thick and hard boride layers can afford very low wear to sliding surfaces under both dry and lubricated conditions [80].

3. Thin surface coatings. Adding a thin layer (typically some few micrometres thick) of another material on the top surface can radically reduce friction and wear. This is often done in vacuum chambers by physical and chemical vapour deposition techniques (PVD and CVD). Strong materials for reducing wear both on tools and in machine components are ceramic coatings such as TiN, CrN, WC/Co, AlTiN, NiSiC, etc. Amorphous and lattice materials such as diamond like carbon (DLC) and molybdenum disulphide $\left(\mathrm{MoS}_{2}\right)$ have been especially efficient in reducing friction even down to a coefficient of friction of 0.01 and below. The thin coatings can be further improved by processing nanostructures and nanolayered coatings [14, 39, 8184]. As a new concept, researchers have also designed smart catalytically active nano-composite layers with an ability to crack long-chain hydrocarbon molecules of base oils and turn them into diamond-like carbon tribofilms and other forms of carbon nanostructures on rubbing surfaces [41]. The resultant tribofilms were proven to be very slick and highly protective against wear and if and when worn away, they were shown to self-heal by a catalytic reaction with the lubricant.

4. Thick composite surface coatings. Thermal spraying, welded overlays, cladding and electroplating are examples of techniques used to reduce wear in heavily loaded conditions. The coating thickness is typically in the range of $0.1-50 \mathrm{~mm}$. The surface is improved by the new material added which often may have a composite structure. Generally, the wear resistance of the coatings increases with their density and cohesive strength. Composite structures with carbide particles embedded into an often metallic matrix with higher elasticity and toughness provide good wear protection. A porous surface structure can be beneficial in lubricated sliding contacts as the oil pockets in pores can improve the lubrication and avoid starvation. Popular coatings to provide good wear resistance are, e.g., WC/Co, $\mathrm{WC} / \mathrm{Ni}, \mathrm{WC} / \mathrm{CoCr}$, $\mathrm{CrC} / \mathrm{NiCr}$, and Co-Cr-Si-Mo alloys [29, 85-89].

\subsection{Component design}

The design of components and the mechanical system has a great influence on both friction and wear. Tribology is a fairly new and evolving field of technology so it is still common that friction and wear aspects have been poorly considered as design criteria for mechanical systems. With proper tribological design can, e.g., the stresses in loaded contacts be reduced, lubricant access be improved, the contact space and number of contacts be reduced, lubrication mechanisms be optimised and severe wear mechanisms be avoided. Below is given only a few examples of tribological solutions for improved component design:

1. Surface texturing. The roughness and surface topography have a remarkable influence on friction and wear. Properly designed dimples, grooves and protrusions prepared on micro- or nanoscale can have a very beneficial effect. The controlled lubricant flow on microscale improves load carrying capacity and reduces friction. Laser surface texturing of piston rings has reduced fuel consumption of engines by $4 \%$ and micro-dimples produced by fine particle shot-peening has reduced friction by up to $50 \%$ [90-96].

2. Micro sensors and actuators. The engines in road transportation run in transient conditions with big changes in load and speed conditions over a broad operating range and the properties of the lubricant degrades due to time and operational effects. For this reason, the engines are typically over-designed to meet the worst possible conditions. With implementing modern micro sensors and actuators can the actual operating conditions continuously be recorded and allow for example the bearing system to be adjusted to optimise design characteristics throughout the operating range of the engine as an compensatory 
strategy for mechanical wear protection. New design can allow the adjustment of the bearing area to the highest loaded region of a journal bearing. This allows modulation of bearing load capacity and its inherent friction loss [12, 97, 98].

\subsection{New methodologies}

The design of tribological components for optimal friction and wear performance is a very complex task if all relevant influencing variables and interactions are properly considered over scales from nano- to macro level. Traditional design includes consideration of some of the main parameters but new methodologies make it possible to perform a more accurate and comprehensive optimisation and consider a larger range of interactions and effects. Three important and rapidly evolving new methodologies are:

\section{Integrated computational material engineering}

(ICME). Multiscale integrated material modelling and simulation based on sophisticated computer codes, finite element and other advanced modelling techniques offers a new tool for design of tribological contacts. The interactions of material behaviour, coatings and composite structures and lubricant mechanisms can be modelled over relevant scales and the performance and durability optimised with a comprehensive approach. Tribologically important but complicated features such as surface topography, thin surface films and substrate microstructures have been integrated in a 3D computer model with relevant data from nano to macro scale and used for simulation of tribological performance [99-102].

2. Nanotechnology. Tribological components have traditionally been designed on macroscale based on micro and macroscale understanding of the tribological contacts. Nanotechnology with molecular, atomic and even subatomic scale tools for material characterisation, computational modelling and even empirical testing makes it possible to investigate the basic physical and chemical contact mechanisms [103]. This information can then be used for more accurate and rigid tribological design. Besides the enhanced understanding of fundamental friction and wear mechanisms through advanced modelling and simulation approaches, many research efforts have also explored the potential usefulness of all kinds of nanomaterials for controlling friction and wear in powder and colloidal forms. Much of these studies focused on graphene and other 2D materials like h-BN, $\mathrm{MoS}_{2}$, etc. Out of these studies, a large body of knowledge have emerged in recent years. When the cost, reliability and environmental health and safety issues have been addressed, it looks that these materials may provide great opportunities for all kinds of tribological applications [104-106].

3. Biomimetics. The nature has solved the task of controlling friction and wear in many genius ways far beyond what modern technology can offer. The hierarchical multiscale organisation and use of composite multiscale structures provides biological systems with the flexibility needed to adapt to the changing environment. The biological materials are grown without final design specifications, but by using the recipes and recursive algorithms contained in their genetic code. The remarkable properties of the biological materials can serve as source of inspiration for new technological solutions. A number of ideas for biomimetic tribological design and materials have been suggested such as the lotus effect for non-adhesive surfaces, the Gecko effect for controlled adhesion, the scorpion effect for reduced erosive wear, the sharkskin effect for suppression of turbulence, the Darkling beetle effect for water capturing, the sand fish lizard effect for moving in loose sand, dynamically tuneable surfaces for controlled liquid vs matter flow, microtextured surfaces for controlled friction, as well as self-lubricating, self-cleaning, self-healing and de-icing biomimetic surfaces [16].

\section{Discussion}

\subsection{Development over the last 50 years}

In the Jost report [1] it was concluded that 515 million UK pounds can be saved annually after ten years of intensive and large scale implementation of new tribological technology in the UK industry. The structure of the savings is shown in Fig. 13. Much of this implementation has been done by different actions both from the government and private sector. The figure also shows the corresponding potential savings in UK today, 50 years later, calculated from 
the data generated in this work. It shows that still today it would be possible achieve about the same level of savings by implementing new technology. The estimated savings in 1966 were $1.36 \%$ of GNP and today they would be $1.39 \%$ of the GNP. This can sound surprising since much technology has already been implemented over the last 50 years.

The explanation can be found when studying the structure of the savings. Fifty years ago $95 \%$ of the savings were related to wear, wear failures, breakdown and lifetime costs. The machines and equipment have over the years developed very much by new technology and they are now much more reliable, failure and breakdown is rare and maintenance costs are low. This can be seen from the figure.

It is interesting to note that fifty years ago it was estimated that $20 \%$ of the savings would come from increased lifetime but in our calculations of today that component has been considered negligible. Our understanding is that this is explained by the present situation that wear out of products is not anymore the main reason for buying a new product. Even if a car would last for 100 years, who would like to drive in the same car the whole lifetime? Even if the products still function people want to buy new products because of new design, new colours, new added functions like automation, new IT-communication possibilities and net connections, etc.

Another important observation is that the role of friction in cost savings has grown from $5 \%$ to $74 \%$. We understand that there are two explanations for this. One is that especially over the last twenty years there have been new scientific and technological findings resulting in a breakthrough in friction reduction that could by no way have been predicted fifty years ago. In tribology textbooks written some thirty years ago it was commonly stated that the lowest coefficient of friction between two solid surfaces is 0.08 in a UHMWPE (common trademark Teflon) polymeric contact. Today superlubricity is an established field of tribology where coefficients of friction even down to 0.0001 have been reported.

The second explanation is that the role of energy consumption is much more important today. If there was high friction in some device in the old days you

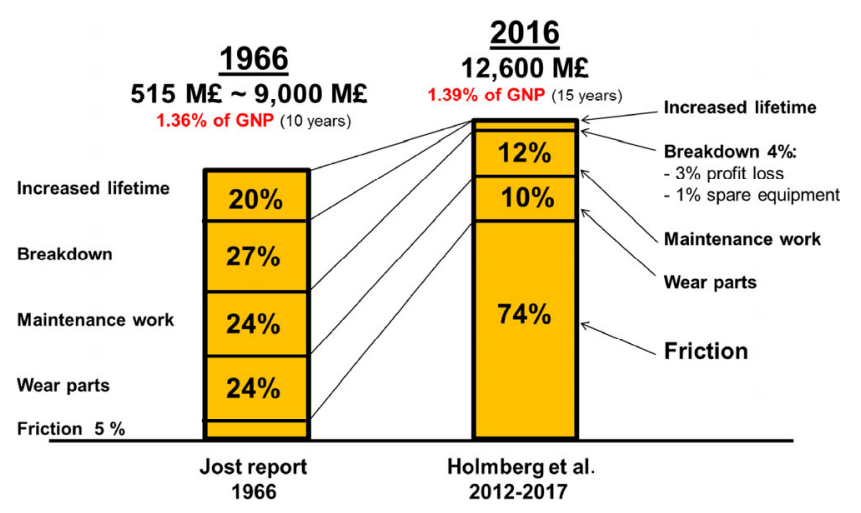

Fig. 13 Potential savings in UK 1966 and 2016 by implementing new tribology in machines and equipment, 515 million UK pounds converts to 9,000 million UK pounds of 2017 value.

just put in more power to overcome the friction. It could well be done with low energy prices. Today we need to be much more cautious with the energy consumption due to limited recourses, higher prices and greenhouse gas emissions.

The recent US report on tribological opportunities for enhancing America's energy efficiency [12] in the future presents new calculations and technologies for energy savings that are in line with this work. They identify $20 \mathrm{EJ}(=2.1 \%$ of the GNP) of energy that could be saved annually through technologies enabled by targeted research support in tribology. Areas where breakthroughs in tribology is needed to achieve this are low viscosity and intelligent lubricants, self-healing ultrathin tribofilms, advanced sensors and actuators for lubricant delivery modulation, nanomaterial fillers in tires, high temperature bearing lubricants, reliable wind turbine drive trains, nanoelectromechanical switches, triboelectric nanogenerators and vapour phase lubrication.

\subsection{Confidence in the used method, data and sources}

In the four previously published case studies on passenger cars, trucks and buses, paper machines and mining industry, we calculated in great detail the friction losses from microscale tribological contacts considering the prevailing friction and lubrication mechanisms. The wear was calculated by correlating energy costs for friction losses to costs for wear and actions due to wear failures. The accuracy of the calculations depends on the accuracy of the data that we could extract from open sources. In many cases 
we have found good statistical data to use but there have also been cases of lack of reliable data that were needed. In such cases we have used estimations based on our best expert understanding. A summary of main results from the studies is in Appendix 3.

Especially for the calculations of friction and wear impact in the four economic sectors there has been little data available on the whole sector related to tribological impact. In some areas like in transportation there is very good and detailed statistical data that can be used even if data on global scale is missing. In some other areas, like in, e.g., rock mining or residential there is very little useful data available. In these areas we have studied the structure of the machinery and equipment used and correlated it to the area where we have detailed information in the four case studies.

We have all the way through the calculation process crosschecked our results with data from available sources and made corrections accordingly. Thus we are convinced that the results from the calculations are in the right order of magnitude and show the relevant trends even if the absolute values should not be considered as precise.

\section{Conclusions}

Calculations of the impact of friction and wear on energy consumption, economic expenditure, and $\mathrm{CO}_{2}$ emissions are presented on a global scale. This impact study covers the four main energy consuming sectors: transportation, manufacturing, power generation, and residential. Previously published four case studies on passenger cars, trucks and buses, paper machines and the mining industry were included in our detailed calculations as reference data in our current analyses. The following can be concluded:

- In total, $23 \%$ (119 EJ) of the world's total energy consumption originates from tribological contacts. Of that $20 \%$ (103 EJ) is used to overcome friction and 3\% (16 EJ) is used to remanufacture worn parts and spare equipment due to wear and wear-related failures.

- By taking advantage of the new surface, materials, and lubrication technologies for friction reduction and wear protection in vehicles, machinery and other equipment worldwide, energy losses due to friction and wear could potentially be reduced by $40 \%$ in the long term ( 15 years)and by $18 \%$ in the short term (8 years). On global scale, these savings would amount to $1.4 \%$ of the GDP annually and $8.7 \%$ of the total energy consumption in the long term.

- The largest short term energy savings are envisioned in transportation (25\%) and in the power generation (20\%) while the potential savings in the manufacturing and residential sectors are estimated to be $\sim 10 \%$. In the longer terms, the savings would be $55 \%, 40 \%$, $25 \%$ and $20 \%$, respectively.

- Implementing advanced tribological technologies can also reduce the $\mathrm{CO}_{2}$ emissions globally by as much as $1,460 \mathrm{MtCO}_{2}$ and result in 450,000 million Euros cost savings in the short term. In the longer term, the reduction can be $3,140 \mathrm{MtCO}_{2}$ and the cost savings 970,000 million Euros.

Fifty years ago, wear and wear-related failures were a major concern for UK industry and their mitigation was considered to be the major contributor to potential economic savings by as much as $95 \%$ in ten years by the development and deployment of new tribological solutions. The corresponding estimated savings are today still of the same orders but the calculated contribution to cost reduction is about $74 \%$ by friction reduction and to $26 \%$ from better wear protection. Overall, wear appears to be more critical than friction as it may result in catastrophic failures and operational breakdowns that can adversely impact productivity and hence cost.

\section{Acknowledgements}

This study has been carried out as part of the Finnish joint industrial consortium strategic research action coordinated by DIMECC Ltd within the program on Breakthrough Materials called BSA in the O'DIGS Project. We gratefully acknowledge the financial support of Tekes, the Finnish Technology Agency, the participating companies, and VTT Technical Research Centre of Finland. Additional support was provided by the U.S. Department of Energy, Basic Energy Sciences and Office of Energy Efficiency and Renewable Energy, under contract DE-AC02-06CH11357. 


\section{Appendix 1 Friction and wear impact on global energy loss, costs and emissions}

\begin{tabular}{|c|c|c|c|c|c|c|c|c|c|c|c|c|c|}
\hline \multirow{2}{*}{\begin{tabular}{|l|} 
Average 2017 \\
Parameter \\
\end{tabular}} & \multirow{2}{*}{\begin{tabular}{|l|} 
Total \\
Energy
\end{tabular}} & \multirow{2}{*}{\begin{tabular}{|l|} 
Friction \\
Share \\
\end{tabular}} & \multirow[b]{2}{*}{ Energy } & \multirow[b]{2}{*}{ Cost } & \multirow[b]{2}{*}{ Emission } & \multirow{2}{*}{$\begin{array}{l}\text { Wear } \\
\text { Share }\end{array}$} & \multirow[b]{2}{*}{ Energy } & \multirow[b]{2}{*}{ Cost } & \multirow[b]{2}{*}{ Emission } & \multicolumn{2}{|c|}{ Tribology total } & \multirow[b]{2}{*}{ Cost } & \multirow[b]{2}{*}{ Emission } \\
\hline & & & & & & & & & & Share & Energy & & \\
\hline Unit & PJ & $\%$ & PJ & MEuro & $\mathrm{MtCO}_{2}$ & $\%$ & PJ & MEuro & $\mathrm{MtCO}_{2}$ & $\%$ & PJ & MEuro & $\mathrm{MtCO}_{2}$ \\
\hline Transportation & 110000 & 30 & 33000 & 594000 & 2254 & & 3300 & 130680 & 225 & & 36300 & 724680 & 2479 \\
\hline Industry & 116000 & 20 & 23200 & 417600 & 1585 & & 3248 & 146160 & 222 & & 26448 & 563760 & 1806 \\
\hline Energy industry & 167000 & 20 & 33400 & 601200 & 2281 & & 7348 & 318636 & 502 & & 40748 & 919836 & 2783 \\
\hline Residential etc。 & 135000 & 10 & 13500 & 243000 & 922 & & 1890 & 85050 & 129 & & 15390 & 328050 & 1051 \\
\hline Total & 528000 & & 103100 & 1855800 & 7042 & & 15786 & 680526 & 1078 & & 118886 & 2536326 & 8120 \\
\hline New 2017 & Total & Friction & & & & Wear & & & & \multicolumn{2}{|c|}{ Tribology total } & & \\
\hline Parameter & energy & share & energy & cost & emission & share & energy & cost & emission & share & energy & cost & emission \\
\hline Unit & PJ & $\%$ & PJ & MEuro & $\mathrm{MtCO}_{2}$ & $\%$ & PJ & MEuro & $\mathrm{MtCO}_{2}$ & $\%$ & PJ & MEuro & $\mathrm{MtCO}_{2}$ \\
\hline Transportation & 95817 & 21 & 19800 & 356400 & 1352 & & 2317 & 91737 & 158 & & 22117 & 448137 & 1511 \\
\hline Industry & 105421 & 13 & 13920 & 250560 & 951 & & 1949 & 87696 & 133 & & 15869 & 338256 & 1084 \\
\hline Energy industry & 151450 & 13 & 20040 & 360720 & 1369 & & 5158 & 223682 & 352 & & 25198 & 584402 & 1721 \\
\hline Residential etc。 & 128844 & 6 & 8100 & 145800 & 553 & & 1134 & 51030 & 77 & & 9234 & 196830 & 631 \\
\hline Total & 481532 & & 61860 & 1113480 & 4225 & & 10558 & 454146 & 721 & & 72418 & 1567626 & 4946 \\
\hline Laboratory 2017 & Total & Friction & & & & Wear & & & & \multicolumn{2}{|c|}{ Tribology total } & & \\
\hline Parameter & Energy & Share & Energy & Cost & Emission & Share & Energy & Cost & Emission & Share & Energy & Cost & Emission \\
\hline Unit & PJ & $\%$ & PJ & MEuro & $\mathrm{MtCO}_{2}$ & $\%$ & PJ & MEuro & $\mathrm{MtCO}_{2}$ & $\%$ & PJ & MEuro & $\mathrm{MtCO}_{2}$ \\
\hline Transportation & 85580 & 12 & 9900 & 178200 & 676 & & 1980 & 78408 & 135 & & 11880 & 256608 & 811 \\
\hline Industry & 95491 & 5 & 4640 & 83520 & 317 & & 1299 & 58464 & 89 & & 5939 & 141984 & 406 \\
\hline Energy industry & 140681 & 7 & 10020 & 180360 & 684 & & 4409 & 191182 & 301 & & 14429 & 371542 & 985 \\
\hline Residential etc。 & 123066 & 2 & 2700 & 48600 & 184 & & 756 & 34020 & 52 & & 3456 & 82620 & 236 \\
\hline Total & 444818 & & 27260 & 490680 & 1862 & & 8444 & 362074 & 577 & & 35704 & 852754 & 2439 \\
\hline Future 2030 & Total & Friction & & & & Wear & & & & \multicolumn{2}{|c|}{ Tribology total } & & \\
\hline Parameter & Energy & Share & Energy & Cost & Emission & Share & Energy & Cost & Emission & Share & Energy & Cost & Emission \\
\hline Unit & PJ & $\%$ & PJ & MEuro & $\mathrm{MtCO}_{2}$ & $\%$ & PJ & MEuro & $\mathrm{MtCO}_{2}$ & $\%$ & PJ & MEuro & $\mathrm{MtCO}_{2}$ \\
\hline Transportation & 81950 & 8 & 6600 & 118800 & 451 & & 1650 & 65340 & 113 & & 8250 & 184140 & 563 \\
\hline Industry & 92846 & 2 & 2320 & 41760 & 158 & & 974 & 43848 & 67 & & 3294 & 85608 & 225 \\
\hline Energy industry & 136606 & 5 & 6680 & 120240 & 456 & & 3674 & 159318 & 251 & & 10354 & 279558 & 707 \\
\hline Residential etc。 & 121527 & 1 & 1350 & 24300 & 92 & & 567 & 25515 & 39 & & 1917 & 49815 & 131 \\
\hline Total & 432929 & & 16950 & 305100 & 1158 & & 6865 & 294021 & 469 & & 23815 & 599121 & 1627 \\
\hline
\end{tabular}

\section{Appendix 2 Savings and reductions by tribology}

\begin{tabular}{|c|c|c|c|c|c|c|c|c|c|c|c|c|c|c|c|c|c|c|}
\hline \multicolumn{3}{|c|}{ Savings and reductions by tribology } & & & & & & & & & \multirow[b]{3}{*}{ Wear } & \multirow[b]{3}{*}{ Total } & & & & & \multirow[b]{3}{*}{ Wear } & \multirow[b]{3}{*}{ Total } \\
\hline Short term, 8 years & \multicolumn{2}{|c|}{ Energy losses } & \multicolumn{2}{|c|}{ Energy savings } & & \multirow[b]{2}{*}{ Total } & \multirow{2}{*}{$\begin{array}{l}\text { Costs } \\
\text { Friction }\end{array}$} & \multirow[b]{2}{*}{ Wear } & \multicolumn{2}{|c|}{ Costs savings } & & & \multicolumn{2}{|c|}{ Emissions } & \multicolumn{2}{|c|}{ Emission savings } & & \\
\hline Parameter & Friction & Wear & Reduction & Friction & Wear & & & & Reduction & Friction & & & Friction & Wear & Reduction & Friction & & \\
\hline Unit & PJ & PJ & $\%$ & PJ & PJ & PJ & MEuro & MEuro & $\%$ & MEuro & MEuro & MEuro & $\mathrm{MtCO}_{2}$ & $\mathrm{MtCO}_{2}$ & $\%$ & $\mathrm{MtCO}_{2}$ & $\mathrm{MtCO}_{2}$ & $\mathrm{MtCO}_{2}$ \\
\hline Transportation & 33000 & 3300 & 25 & 8250 & 825 & 9075 & 594000 & 130680 & 25 & 148500 & 32670 & 181170 & 2254 & 225 & 25 & 563 & 56 & 620 \\
\hline Industry & 23200 & 3248 & 10 & 2320 & 325 & 2645 & 417600 & 146160 & 10 & 41760 & 14616 & 56376 & 1585 & 222 & 10 & 158 & 22 & 181 \\
\hline Energy industry & 33400 & 7348 & 20 & 6680 & 1470 & 8150 & 601200 & 318636 & 20 & 120240 & 63727 & 183967 & 2281 & 502 & 20 & 456 & 100 & 557 \\
\hline Residential etc. & 13500 & 1890 & 10 & 1350 & 189 & 1539 & 243000 & 85050 & 10 & 24300 & 8505 & 32805 & 922 & 129 & 10 & 92 & 13 & 105 \\
\hline Total & 103100 & 15786 & 18 & 18600 & 2808 & 21408 & 1855800 & 680526 & 16 & 334800 & 119518 & 454318 & 7042 & 1078 & 16 & 1270 & 192 & 1462 \\
\hline Long term, 15 years & \multicolumn{2}{|l|}{ Energy losses } & \multicolumn{2}{|c|}{ Energy savings } & & & Costs & & \multicolumn{2}{|c|}{ Costs savings } & & & \multicolumn{2}{|c|}{ Emissions } & \multicolumn{2}{|c|}{ Emission savings } & & \\
\hline Parameter & Friction & Wear & Reduction & Friction & Wear & Total & Friction & Wear & Reduction & Friction & Wear & Total & Friction & Wear & Reduction & Friction & Wear & Total \\
\hline Unit & PJ & PJ & $\%$ & PJ & PJ & PJ & MEuro & MEuro & $\%$ & MEuro & MEuro & MEuro & $\mathrm{MtCO}_{2}$ & $\mathrm{MtCO}_{2}$ & $\%$ & $\mathrm{MtCO}_{2}$ & $\mathrm{MtCO}_{2}$ & $\mathrm{MtCO}_{2}$ \\
\hline Transportation & 33000 & 3300 & 55 & 18150 & 1815 & 19965 & 594000 & 130680 & 55 & 326700 & 71874 & 398574 & 2254 & 225 & 55 & 1240 & 124 & 1364 \\
\hline Industry & 23200 & 3248 & 25 & 5800 & 812 & 6612 & 417600 & 146160 & 25 & 104400 & 36540 & 140940 & 1585 & 222 & 25 & 396 & 55 & 452 \\
\hline Energy industry & 33400 & 7348 & 40 & 13360 & 2939 & 16299 & 601200 & 318636 & 40 & 240480 & 127454 & 367934 & 2281 & 502 & 40 & 912 & 201 & 1113 \\
\hline Residential etc. & 13500 & 1890 & 20 & 2700 & 378 & 3078 & 243000 & 85050 & 20 & 48600 & 17010 & 65610 & 922 & 129 & 20 & 184 & 26 & 210 \\
\hline Total & 103100 & 15786 & 39 & 40010 & 5944 & 45954 & 1855800 & 680526 & 35 & 720180 & 252878 & 973058 & 7042 & 1078 & 35 & 2733 & 406 & 3139 \\
\hline
\end{tabular}


Appendix 3 Summary of friction and wear savings as calculated in five studies $[15,17-19]$

\begin{tabular}{|c|c|c|c|c|c|c|c|c|c|c|c|c|}
\hline & \multicolumn{2}{|c|}{ Term } & \multicolumn{2}{|c|}{ Savings } & \multicolumn{2}{|c|}{ Economic savings } & \multicolumn{2}{|c|}{ Emission reduction } & \multicolumn{2}{|c|}{ Energy savings } & \multirow{2}{*}{$\begin{array}{c}\text { Part of global } \\
\text { energy }\end{array}$} & \multirow{2}{*}{$\begin{array}{l}\text { Included in } \\
\text { calculations }\end{array}$} \\
\hline & years & years & $\%$ & $\%$ & GEuro & GEuro & $\mathrm{MtCO}_{2}$ & $\mathrm{MtCO}_{2}$ & EJ & EJ & & \\
\hline Passenger cars, 2012 & 7.5 & 20 & 18 & 61 & 174 & 576 & 290 & 960 & 4 & 13.5 & 7.5 & Friction \\
\hline Trucks \& buses, 2014 & 6 & 10 & 14 & 37 & 105 & 280 & 200 & 530 & 2.6 & 7.2 & 4.5 & Friction \\
\hline Paper machines, 2013 & 10 & 22.5 & 11 & 23.6 & 2 & 4.2 & 11 & 23 & 0.036 & & 1 & Friction \\
\hline Mining industry, 2017 & 10 & 20 & 15 & 30 & 31 & 62 & 145 & 290 & 1 & 2 & 2.3 & Friction \& wear \\
\hline World total 2017 & 8 & 15 & 15 & 30 & 410 & 830 & 2800 & 5700 & 19 & 39 & 100 & Friction \& wear \\
\hline World energy consumption, EJ & 528 & & & & & & & & & & & \\
\hline - Savings, $\%$ of world energy & 4.1 & 8.7 & & & & & & & & & & \\
\hline World GDP, GEuro & 70,000 & & & & & & & & & & & \\
\hline - Savings, $\%$ of GDP & 0.65 & 1.39 & & & & & & & & & & \\
\hline World emission, $\mathrm{MtCO}_{2}$ & 36,000 & & & & & & & & & & & \\
\hline - Savings, $\%$ of all $\mathrm{CO}_{2}$ emiss. & 4.1 & 8.7 & & & & & & & & & & \\
\hline
\end{tabular}

\section{Appendix 4 Conversion factors}

\section{Energy conversions}

$1 \mathrm{kWs} \quad=1 \mathrm{~kJ}$

$1 \mathrm{kWh} \quad=3.6 \mathrm{MJ}$

$1 \mathrm{Mtoe}=$ million tonnes of oil equivalent

1 Mtoe $=41,868 \mathrm{TJ}$

$1 \mathrm{Btu}=1,055 \mathrm{~J}$

$1 \mathrm{Quad}=1.055 \mathrm{EJ}$

$1 \mathrm{kWh}=0.06$ Euro as global average 2014

1 hour labour $=6$ Euro salary cost as global average 2014

$1 \mathrm{PJ} \quad \Rightarrow$ result in $0.0683 \mathrm{MtCO}_{2}$ emissions

$1 \mathrm{PJ} \quad \Rightarrow>$ has the price of $18 \mathrm{M€}$

Diesel fuel conversions

1 liter $\quad=0.832 \mathrm{~kg}$

$1 \mathrm{MJ} \quad=0.028$ liter

1 liter $\quad=35.9 \mathrm{MJ}$

$1 \mathrm{~kg} \quad=43.1 \mathrm{MJ}$

$1 \mathrm{~kg} \quad \Rightarrow 3.16 \mathrm{~kg} \mathrm{CO}_{2}$ emission

1 liter $\quad \Rightarrow 2.63 \mathrm{~kg} \mathrm{CO}_{2}$ emission

1 liter $\quad=0.7$ Euro as global average 2014

Open Access: The articles published in this journal are distributed under the terms of the Creative Commons Attribution 4.0 International License (http:// creativecommons.org/licenses/by/4.0/), which permits unrestricted use, distribution, and reproduction in any medium, provided you give appropriate credit to the original author(s) and the source, provide a link to the Creative Commons license, and indicate if changes were made.

\section{References}

[1] Jost H P (ed.). Lubrication (Tribology)-A report on the present position and industry's needs. Department of Education and Science, H. M. Stationary Office, London, UK, 1966.

[2] Jost H P. Economic impact of tribology. National Bureau of Standards special publication 423. In Proc. $20^{\text {th }}$ Meeting of the Mechanical Failures Prevention Group. Gaithersburg, USA, 1974.

[3] Jost H P, Schoefield J. Energy saving through tribology: A techno-economic study. Proc Instn Mech Engrs 195: 151-173 (1981)

[4] Jost P H. Tribology-Origin and future. Wear 136:1-17(1990)

[5] JSPMI. State-of-art report on lubrication practice in Japan (in Japanese). Technical Research Institute, Japan Society for the Promotion of Machine Industry, Japan, Research Report, 1970.

[6] Research Report T76-36 Tribologie (Code BMFT-FB-T7636). Bundesministerium fur Forschung und Technologie (Federal Ministry for Research and Technology), West Germany, 1976.

[7] ASME 1977. Strategy for energy conservation through tribology. ASME, New York, 1977

[8] ASME 1981. Strategy for energy conservation through tribology. $2^{\text {nd }}$ edition, ASME, New York, 1977

[9] China 1986. An investigation on the application of tribology in China. A report by the Tribology Institution of the Chinese Mechanical Engineering Society, September 1986, Beijing, China. 
[10] IPCC 2014. Climate Change 2014: Impacts, Adaptation and Vulnerability. Summary for policy makers, $5^{\text {th }}$ Assessment report of the intergovernmental panel on climate change, WMO, UNEP, 2014.

[11] Wiedmann T O, Schandl H, Lenzen M, Moran D, Suh S, West J, Kanemoto K. The material footprint of nations. PNAS 112: 6271-6276 (2015)

[12] Lee P M, Carpick R (eds). Tribological opportunities for enhancing America's energy efficiency. A report to the Advanced Research Projects Agency-Energy (ARPA-E) at the U.S. Department of Energy, 14.2.2017.

[13] IEA Energy Technology Persectives 2010. Scenarios \& Strategies to 2050 IEA International Energy Agency, Paris, France 2010.

[14] Cha S C, Erdemir A (eds). Coating Technology for Vehicle Applications. Springer Verlag, Heidelberg, 2015.

[15] Holmberg K, Kivikytö-Reponen P, Härkisaari P, Valtonen K, Erdemir A. Global energy consumption due to friction and wear in the mining industry. Tribology International 115:116-139 (2017)

[16] Nosonovsky M, Bhushan B. Green Tribology - Biomimetics, Energy Conservation and Sustainability. Springer Verlag, Berlin, Germany, 2012.

[17] Holmberg K, Andersson P, Erdemir A. Global energy consumption due to friction in passenger cars. Tribology International 47: 221-234 (2012)

[18] Holmberg K, Siilasto R, Laitinen T, Andersson P, Jäsberg A. Global energy consumption due to friction in paper machines. Tribology International 62: 58-77 (2013)

[19] Holmberg K, Andersson P, Nylund P O, Mäkelä K, Erdemir A. Global energy consumption due to friction in trucks and buses. Tribology International 78: 94-114 (2014)

[20] IEA Key World Energy Statistics 2016. International Energy Agency, Paris, France, 2010.

[21] WEC, Global Transport Scenarios 2050. World Energy Council, London, UK, 2011.

[22] Komonen K. Maintenance key numbers-Results from 2002 year survey/Kunnossapidon tunnuslukuja-Vuotta 2002 koskevan kyselyn tuloksia (in Finnish), Finnish Maintenance Society, Helsinki, Finland, 2003.

[23] IEA Tracking Industrial Energy Efficiency and $\mathrm{CO}_{2}$ Emissions-Energy Indicators. International Energy Agency, Paris, France, 2007.

[24] Erdemir A, Holmberg K. Energy consumption due to friction in motored vehicles and low-friction coatings to reduce it. InCoating Technology for Vehicle Applications. Cha S C, Erdemir A (eds). Springer Verlag, Heidelberg, 2015: 1-23.

[25] Mode of transport.Wikipedia, https://en.wikipedia.org/wiki/ Mode_of_transport, 16.5.2017

[26] Rodrigue J P, Comotois C, Slack B. The Geography of
Transport Systems. 3rd edition, Routledge, New York, USA, 2013.

[27] IEA Transport, Enenrgy and $\mathrm{CO}_{2}$-Moving Toward Sustainability. International Energy Agency, Paris, France, 2009.

[28] RITA. Freight Transportation: Global Highlights. US Department of Transportation, Reseacrh and Innovative Technology Administration, RITA Bureau of Transport Statistics, Washington DC, USA, 2010.

[29] Davis J R (Ed.). Surface engineering for corrosion and wear resistance. ASM International, USA, 2001.

[30] EU Transport in figures-Statistical pocketbook 2015. European Union, Brussels, Belgium, 2015.

[31] Davis S C, Diegel S W, Boundy R G. Transportation Energy Data Book. Edition 32, Oak Ridge National Laboratory, Oak Ridge, USA, 2013.

[32] IEA World Energy Outlook 2015. International Energy Agency, Paris, France, 2015.

[33] Barros Bouchet M, Martin J M. The future of boundary lubrication by carbon coatings and environmentally friendly additives. In Advanced Tribology. Luo J, Meng Y, Shao T, Zhao Q (eds). Bejing, China, Tsinghua University Press \& Springer, 2010: 598-599.

[34] Martin J M, Barros Bouchet M I, Sagawa T. Green tribology: Lubricant compliant superhard DLC coatings. In Proceedings of the 4th World Tribology Conference, Kyoto Japan, 2009.

[35] Martin J M, Barros Bouchet M I, Matta C, Zhang Q, Goddard III W A, Okuda S, Sagawa T. Gas-phase lubrication of a ta-C by glycerol and hydrogen peroxide: Experimental and computer modelling. Journal of Physical Chemistry C114: 5003-5011 (2010)

[36] Martin J M, Ohmae N. Nanolubricants. John Wiley \& Sons Ltd., New York, USA, 2008.

[37] Kalin M, Kogovsek J, Remskar M. Mechanisms and improvements in the friction and wear behaviour using $\mathrm{MoS}_{2}$ nanotubes as potential oil additives. Wear 280-281: 36-45 (2012)

[38] Kalin M, Kogovsek J, Remskar M. Nanoparticles as novel lubricating additives in a green, physically based lubrication technology for DLC coatings. Wear 303: 480-485 (2013)

[39] Xu J, Li J. New achievements in superlubricity from International Workshop on Superlubricity: Fundamental and Applications. Friction 3(4): 344-351 (2015)

[40] Dai W, Kheireddin B, Gao H, Liang H. Roles of nanoparticles in oil lubrication. Tribology International 102: 88-98(2016)

[41] Erdemir A, Ramirez G, Eryilmaz O L, Narayanan B, Liao Y, Karmath G, Sankaranarayanan S K. Carbon-based tribofilms from lubricating oils. Nature 536 (7614): 67-71 (2016)

[42] Scherge M, Böttcher R, Linsler D, Kurten D. Multi-phase friction and wear reduction by copper nanoparticles. Lubricants 
4(36):1-13 (2016)

[43] Ge X, Xia Y, Shu Z, Zhao X. Conductive grease synthesized using nanometer ATO as an additive. Friction 3(1): 56-64 (2015)

[44] Tormos B, Ramirez L, Johansson J, Björling M, Larsson R. Fuel consumption and friction benefits of low viscosity engine oils for heavy duty applications. Tribology International 110: 23-34 (2017)

[45] Singh S, Singh S, Sehgal A. Impact of low viscosity engine oil on performance, fuel economy and emissions of light duty diesel engine. No. 2016-01-2316. SAE Technical Paper, 2016

[46] Cuthbert J, Gangopadhyay A, Elie L, Liu Z, Mcwatt D, Hock E D, Erdemir A. Engine friction and wear performances with polyalkylene glycol engine oils. SAE Technical Paper 2016-01-2271

[47] Choo J H, Forrest A K, Spikes H A. Influence of organic friction modifier on liquid slip: A new mechanism of organic friction modifier action. Tribology Letters 27: 239-244 (2007)

[48] Amann T, Kailer A. Ultralow friction of mesogenic fluid mixtures in tribological reciprocating systems. Tribology Letters 37: 343-352 (2010)

[49] Qu J, Truhan J J, Dai S, Luo H, Blau P J. Ionic liquids with ammonium cations as lubricants or additives. Tribology Letters 22: 207-214 (2006)

[50] Qu J, Blau P, Dai S, Luo H, Meyer III H M. Ionic liquids as novel lubricants and additives for diesel engine applications. Tribology Letters 35:181-189 (2009)

[51] Qu J, Blau P, Dai S, Luo H, Meyer III H M, Truhan J J. Tribological characteristics of aluminium alloys sliding against steel lubricated by ammonium and imidazolium liquids. Wear 267: 1226-1231 (2009)

[52] Zhou Y, Qu J. Ionic liquids as lubricant additives: A review. ACS Applied Materials \& Interfaces 9(4): 3209-3222 (2017)

[53] Li J, Zhang C, Ma L, Liu Y, Luo J. Superlubricity achieved with mixtures of acids and glycerol. Langmuir 29: 271-275 (2013)

[54] Luo J, Deng M, Zhang C. Advances of Superlubricity. In Proc. ITS-IFToMM 2017 and K-TIS 2017, Jeju, Korea, 2017.

[55] Zhang Y. An improved hydrodynamic journal bearing with the boundary slippage. Meccanica 50: 25-38 (2015)

[56] Forster N H. Rolling contact testing of vapour phase lubricants-Part III: Surface analysis. Tribology Transactions 42(1): 1-9 (1999)

[57] Argibay N, Keith J H, Krick B A, Hahn D W, Bourne G R, Sawer W G. High-temperature vapour phase lubrication using carbonaceous gases. Tribology Letters 40: 3-9 (2010)

[58] Greiner C, Felts J R, Dai Z, King W P, Carpick R W. Controlling nanoscale friction through the competition between capillary adsorption and thermal activated sliding. AVS Nano
6(5): 4305-4313 (2012)

[59] Berman D, Krim J. Surface science, MEMS and NEMS: Progress and opportunities for surface science research performed on, or by, microdevices. Progress in Surface Science 88: 171-211 (2013)

[60] Kim H J, Seo K J, Kang K H, Kim D E. Nano-lubrication: A review. International Journal of Precision Engineering and Manufacturing 17(6): 829-841 (2016)

[61] Hsu S M, Shen M. Wear prediction of ceramics. Wear 256: 867-878 (2004)

[62] Tsai M H, Yeh J W. High-entropy alloys: A critical review. Materials Research Letters 2(3): 107-123 (2014)

[63] Buluc G, Florea I, Chelariu R, Rusu O, Carcea I. Microstructure and wear resistance of $\mathrm{FeNiCrMnCu}$ high entropy alloy. Trans Tech Publications 1143: 3-6 (2017)

[64] Yu Y, Wang J, Li J, Yang J, KouH, Liu W. Tribological behavior of AlCoCrFeNi (Ti 0.5) high entropy alloys under oil and MACs lubrication. Journal of Materials Science \& Technology 32(5): 470-476 (2016)

[65] Nilufar S. Experimental investigation of structure, composition and properties of novel metal-carbon covetic materials. $\mathrm{PhD}$ dissertation, University of Illinois at Urbana-Champaign, USA, 2014.

[66] Della Corte C. Novel Super-Elastic Materials for Advanced Bearing Applications. In: Advances in Science and Technology, Trans Tech Publications 89: 1-9 (2014)

[67] Qunfeng Z, Dong G, Martin J M. Green superlubricity of Nitinol 60 alloy against steel in presence of castor oil. Scientific Reports 6, 2016.

[68] Bagherifard S, Fernandez-Pariente I, Ghelichi R, Guagliano M. Severe shot peening to obtain nanostructured surfaces: process and properties of the treated surfaces. Handbook of Mechanical Nanostructuring, 299-323(2015)

[69] Unal O, Varol R, Erdogan A, Gok M S. Wear behaviour of low carbon steel after severe shot peening. Materials Research Innovations 17(7): 519-523 (2013)

[70] Besharati-Givi M K, Asadi P. Advances in Friction-stir Welding and Processing. Elsevier, Amsterdam, the Netherlands, 2014.

[71] Seraj R A, Abdollah-Zadeh A, Hajian M, Kargar F, Soltanalizadeh R. Microstructural evolution and wear resistance of friction stir-processed AISI 52100 steel. Metallurgical and Materials Transactions A 47(7): 3564-3572 (2016)

[72] Singh S, Ramakrishna S, Singh R. Material issues in additive manufacturing: A review. Journal of Manufacturing Processes 25: 185-200 (2017)

[73] Frazier W E. Metal additive manufacturing: A review. Journal of Materials Engineering and Performance 23(6): 1917-1928 (2014)

[74] Baig U M, Khan A A, Rajakumar D R. Wear characterization of direct steel-H20 specimens produced by additive 
manufacturing techniques. In Advances in $3 D$ Printing \& Additive Manufacturing Technologies. Wimpenny D I, Pandey P M, Kumar L J (eds). Springer, Singapore, 2017, 121.

[75] Kasonde M, Kanyanta V. Future of superhard material design, processing and manufacturing. In MicrostructureProperty Correlations for Hard, Superhard, and Ultrahard Materials. Kanyanta V (ed.). Springer, Singapore, 2016: 211-239.

[76] Bartolomeu F, Sampaio M, Carvalho O, Pinto E, Alves N, Gomes J R, Miranda G. Tribological behavior of Ti6Al4V cellular structures produced by Selective Laser Melting. Journal of the Mechanical Behavior of Biomedical Materials 2017.

[77] Sundararajan G, Joshi S V, Krishna L R. Engineered surfaces for automotive engine and power train components. Current Opinion in Chemical Engineering 11: 1-6 (2016)

[78] Jacobson S, Hogmark S. Surface modifications in tribological contacts. Wear 266: 370-378 (2009)

[79] Goldbaum D, Poirier D, Irissou E, Legoux J G, Moreau C. Review on Cold Spray Process and Technology US Patents. In Modern Cold Spray. Springer International Publishing, 2015: 403-429.

[80] Timur S, Kartal G, Eryilmaz O L, Erdemir A. U.S. Patent No. 8,951,402. Washington, DC: U.S. Patent and Trademark Office, 2015.

[81] Holmberg K, Matthews A. Coatings Tribology-Properties, Mechanisms, Techniques and Applications in Surface Engineering. Elsevier Tribology and Interface Engineering Elsevier Series. Amsterdam, the Netherlands: Elsevier; 2009.

[82] Berman D, Deshmukh S A, Sankaranarayanan S K R S, Erdemir A, Sumant A V. Macroscale superlubricity enabled by graphene nanoscroll formation. Science express 14 May 2015/10.1126/science.1262024.

[83] Ronkainen H, Elomaa O, Varjus S, Kilpi L, Jaatinen T, Koskinen J. The influence of carbon based coatings and surface finish on the tribological performance in high-load contacts. Tribology International 96: 402-409 (2016)

[84] Yang J, Xia Y, Song H, Chen B, Zhang Z. Synthesis of the liquid-like graphene with excellent tribological properties. Tribology International 105: 118-124 (2017)

[85] Davis J R (Ed.). Handbook of Thermal Spray Technology. TTS ASM Thermal Spray Society, ASM International, USA, 2004.

[86] Gerard B. Application of thermal spraying in the automotive industry. Surface and Coatings Technology 201: 2028-2031 (2006)

[87] Lima R S, Marple B R. Thermal spray coatings engineered from nanostructural ceramic agglomerated powders for structural, thermal barrier and biomedical applications: A review. Journal of Thermal Spray Coatings 16: 40-63(2007)
[88] Pawlowski L. The Science and Engineering of Thermal Spray Coatings. $2^{\text {nd }}$ edition. John Wiley \& Sons, Chichester, England, 2008.

[89] Castro R M, Cavaler L C C, Marques F M, Bristot V M, Rocha A S. Comparative of the tribological performance of hydraulic cylinders coated by the process of thermal spray HVOF and hard chrome plating. Tribology in Industry 36: 79-89 (2014)

[90] Kovalchenko A, Ajayi O O, Erdemir A, Fenske G R, Etsion I. The effect of laser texturing of steel surface and speed-load parameters on lubrication regime transition from boundary to hydrodynamic. Tribology Transactions 47: 299-307 (2004)

[91] Klingerman Y, Etsion I, Shinkarenko A. Improving tribological performance of piston rings by partial surface texturing. Transactions of the ASME, Journal of Tribology 127: 632-638 (2005)

[92] Ryk G, Etsion I. Testing piston rings with partial laser surface texturing for friction reduction. Wear 261: 792-796 (2006)

[93] Etsion I. Surface texturing. In Handbook of Lubrication and Tribology, $2^{\text {nd }}$ edition. Totten G (ed.). CRC Taylor \& Francis, London, UK, Vol 2, Chapter 53, 2012.

[94] Etsion I, Sher E. Improving fuel efficiency with laser surface textured piston rings. Tribology International 42: 542-547 (2009)

[95] Ishida Y, Usami H, Hoshino Y. Effect of micro dimples on frictional properties in boundary lubrication condition. In Proceedings of the World Tribology Congress, Kyoto, Japan, 2009.

[96] Wang X, Yu H, Huang W. Surface texture design for different circumstances. In Proceedings of the 1st International Brazilian Conference on Tribology, TriboBR 2010, Rio de Janeiro, Brazil, 2010: 97-107.

[97] Canter N. Tribocatalysis: A new extreme pressure lubrication approach. Tribology and Lubrication Technology 72(10): 10-11(2016)

[98] Varenberg M, Ryk G, Yakhnis A, Kligerman Y, Kondekar $\mathrm{N}$, McDowell M T. Mechano-chemical surface modification with $\mathrm{Cu}_{2} \mathrm{~S}$ : Including superior lubricity. Tribology Letters 64(28): 1-7 (2016)

[99] Holmberg K, Laukkanen A, Ghabchi A, Rombouts M, Turunen E, Waudby R, Suhonen T, Valtonen K, Sarlin E. Computational modelling based wear resistance analysis of thick composite coatings. Tribology International 72: 13-30 (2014)

[100] Holmberg K, Laukkanen A, Turunen E, Laitinen T. Wear resistance optimisation ofcomposite coatings bycomputational microstructural modelling and simulation. Surface and Coatings Technology 247: 1-13 (2014)

[101] Laukkanen A, Holmberg K, Ronkainen H, Stachowiack 
G, Podsiadlo P, Wolski M, Gee M, Gachot C, Li L. Topographical orientation effects on surface stresses influencing on wear in sliding DLC contacts, Part 2: Modelling and simulations. Wear, in press, 2017.

[102] Schmitz GJ, Prahl U (eds). Handbook of Software Solutions for ICME. Wiley-VCH Verlag GmbH \& Co, Weinheim, Germany, 2017.

[103] Jacobs T D, Carpick R W. Nanoscale wear as a stress-assisted chemical reaction. Nature Nanotechnology 8(2): 108-112 (2013)

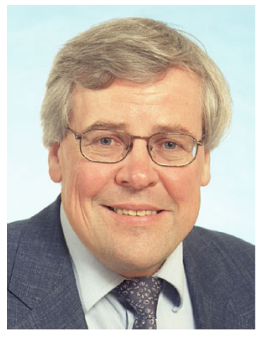

Kenneth HOLMBERG. He is research professor in tribology, condition monitoring and operational reliability at the VTT Technical Research Centre of Finland. He is the author of two books on coating tribology, editor of 16 books and he has given 53 invited plenary/keynote lectures at international conferences. He has published over 200 scientific papers mainly in areas of tribology, surface engineering, lubrication, computational material modelling and simulation, operational reliability, maintenance and diagnostics. He is interim acting president of the International Tribology Council. He is leader of Model based design of tribological coating systems in IEA programme on Advanced Materials for

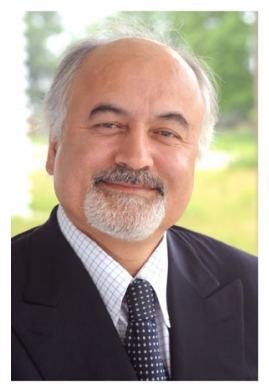

Ali ERDEMIR. He is a distinguished fellow and a senior scientist at Argonne National Laboratory with international recognition and significant accomplishments in the fields of tribology, materials science, and surface engineering. He received his B.S. degree from Istanbul Technical University in 1977 and M.S. and Ph.D. degrees in materials science and engineering from the Georgia Institute of Technology in 1982 and 1986, respectively. In recognition of his pioneering research, Dr. Erdemir has received numerous coveted awards and honors, including six R\&D 100 Awards, Mayo D. Hersey Award
[104] Berman D, Erdemir A, Sumant A V. Graphene: A new emerging lubricant. Materials Today 17(1): 31-42 (2014)

[105] Khare V, Pham M Q, Kumari N, Yoon H S, Kim C S, Park J I, Ahn S H. Graphene-ionic liquid based hybrid nanomaterials as novel lubricant for low friction and wear. ACS Applied Materials \& Interfaces 5(10): 4063-4075 (2013)

[106] Spear J C, Ewers B W, Batteas J D. 2D-nanomaterials for controlling friction and wear at interfaces. Nano Today 10(3): 301-314 (2015)

Transportation 2012-2017. He was president of the OECD IRG Wear group 1992-2006 and chairman of the European COST 516\&532 TRIBOLOGY joint research actions 1995-2008. He is chief engineer councillor at the Supreme Administrative Court of Finland and a frequently used expert in the European community and European Science Foundation research actions and programmes. He is member of the Board of Directors at the Taiho Kogyo Tribology Research Foundation (Japan), member of the Programme Committee for Materials Research at the Foundation of Strategic Research (Sweden), and a frequently used consultant for industrial contracts and R\&D projects. At VTT he is presently coordinating the strategic computational materials modelling and simulation research, VTT Propertune.

of ASME, two Al Sonntag Awards and an Edmond E. Bisson Award from the Society of Tribologists and Lubrication Engineers (STLE). He is the past president of STLE and a fellow of ASME, STLE, AVS, and ASM-International. He has authored/co-authored more than 300 research articles (260 of which are peer-reviewed) and $18 \mathrm{book} / \mathrm{handbook}$ chapters, edited three books, presented more than 160 invited/ keynote/plenary talks, and holds 19 U.S. patents. His current research is directed toward nano-scale design and large-scale manufacturing of new materials, coatings, and lubricants for a broad range of applications in transportation, manufacturing, and other energy conversion and utilization systems. 